\title{
The Norwegian Earth System Model, NorESM1-M - Part 2: Climate response and scenario projections
}

\author{
T. Iversen ${ }^{1,2, *}$, M. Bentsen ${ }^{3,4}$, I. Bethke ${ }^{3,4}$, J. B. Debernard ${ }^{1}$, A. Kirkevåg ${ }^{1}$, Ø. Seland ${ }^{1}$, H. Drange ${ }^{5,4}$,

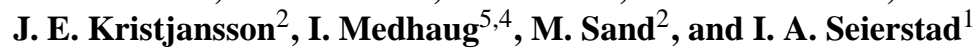 \\ ${ }^{1}$ Norwegian Meteorological Institute, P.O. Box 43, Blindern, 0313 Oslo, Norway \\ ${ }^{2}$ Department of Geosciences, University of Oslo, P.O. Box 1047, Blindern, 0315 Oslo, Norway \\ ${ }^{3}$ Uni Bjerknes Centre, Uni Research AS, P.O. Box 7810, 5020 Bergen, Norway \\ ${ }^{4}$ Bjerknes Centre for Climate Research, P.O. Box 7810, 5020 Bergen Norway \\ ${ }^{5}$ Geophysical Institute, University of Bergen, P.O. Box 7803, 5020 Bergen, Norway \\ * currently at: ECMWF, Shinfield Park, Reading, RG2 9AX, UK \\ Correspondence to: T. Iversen (trond.iversen@met.no)
}

Received: 26 July 2012 - Published in Geosci. Model Dev. Discuss.: 14 September 2012

Revised: 11 January 2013 - Accepted: 4 February 2013 - Published: 22 March 2013

\begin{abstract}
NorESM is a generic name of the Norwegian earth system model. The first version is named NorESM1, and has been applied with medium spatial resolution to provide results for CMIP5 (http://cmip-pcmdi.llnl.gov/cmip5/index. html) without (NorESM1-M) and with (NorESM1-ME) interactive carbon-cycling. Together with the accompanying paper by Bentsen et al. (2012), this paper documents that the core version NorESM1-M is a valuable global climate model for research and for providing complementary results to the evaluation of possible anthropogenic climate change. NorESM1-M is based on the model CCSM4 operated at NCAR, but the ocean model is replaced by a modified version of MICOM and the atmospheric model is extended with online calculations of aerosols, their direct effect and their indirect effect on warm clouds. Model validation is presented in the companion paper (Bentsen et al., 2012). NorESM1-M is estimated to have equilibrium climate sensitivity of ca. $2.9 \mathrm{~K}$ and a transient climate response of ca. $1.4 \mathrm{~K}$. This sensitivity is in the lower range amongst the models contributing to CMIP5. Cloud feedbacks dampen the response, and a strong AMOC reduces the heat fraction available for increasing near-surface temperatures, for evaporation and for melting ice. The future projections based on RCP scenarios yield a global surface air temperature increase of almost one standard deviation lower than a 15-model average. Summer sea-ice is projected to decrease considerably by 2100 and disappear completely for RCP8.5. The AMOC is projected
\end{abstract}

to decrease by $12 \%, 15-17 \%$, and $32 \%$ for the RCP2.6, $4.5,6.0$, and 8.5 , respectively. Precipitation is projected to increase in the tropics, decrease in the subtropics and in southern parts of the northern extra-tropics during summer, and otherwise increase in most of the extra-tropics. Changes in the atmospheric water cycle indicate that precipitation events over continents will become more intense and dry spells more frequent. Extra-tropical storminess in the Northern Hemisphere is projected to shift northwards. There are indications of more frequent occurrence of spring and summer blocking in the Euro-Atlantic sector, while the amplitude of ENSO events weakens although they tend to appear more frequently. These indications are uncertain because of biases in the model's representation of present-day conditions. Positive phase PNA and negative phase NAO both appear less frequently under the RCP8.5 scenario, but also this result is considered uncertain. Single-forcing experiments indicate that aerosols and greenhouse gases produce similar geographical patterns of response for near-surface temperature and precipitation. These patterns tend to have opposite signs, although with important exceptions for precipitation at low latitudes. The asymmetric aerosol effects between the two hemispheres lead to a southward displacement of ITCZ. Both forcing agents, thus, tend to reduce Northern Hemispheric subtropical precipitation. 


\section{Introduction}

Simulations of the Earth's climate are presented using a version of the Norwegian Earth System Model (NorESM1-M) with online calculations of aerosols and their direct effect and the first and second indirect effects of warm clouds. In the companion paper by Bentsen et al. (2012) the NorESM1$\mathrm{M}$ model system is described in technical detail and validated through the evaluation of its conservative properties and by comparing simulation results with observationally based data for the historical period since 1850 . The present paper focuses on the simulated response of NorESM1-M to a selection of experiments, including projections of the future global climate based on scenarios defined in the fifth phase of the Coupled Model Intercomparison Project (CMIP5) (Taylor et al., 2012). Although carbon cycling is included in the ocean and land models of NorESM1-M, another version of NorESM1, called NorESM1-ME, is used to simulate the Earth's climate with an interactive carbon cycle as described by Tjiputra et al. (2013).

A range of climate models and climate model versions participate in CMIP5, thereby providing input to the fifth Assessment Report (AR5) of the Intergovernmental Panel on Climate Change (IPCC) scheduled for publication in 2013. All data produced by the participating models, including NorESM1-M, can be downloaded from the CMIP5 multimodel data archive (http://cmip-pcmdi.llnl.gov/cmip5/index. html).

The main purpose of this paper is to establish that results from the CMIP5 experiments with NorESM1-M are valuable for the climate system science and the evaluation of possible anthropogenic influences on the global climate. The model and the model simulations are briefly summarised in Sect. 2 . After discussing climate sensitivity, response and gross feedbacks in Sect. 3, the present paper addresses aspects of the historical simulations and the RCP scenarios produced with NorESM1-M. Section 4 discusses model simulated timedevelopments of global variables from 1850 to 2005 ("Historic") and onwards for future RCP projections. In Sect. 5, the single forcing experiments for 1850-2005 are addressed, whilst further discussions of the RCP scenario projections are done in Sect. 6. After an analysis of various regional climate patterns are done in Sect. 7, conclusions are drawn in Sect. 8.

\section{The model and model simulations}

As elaborated by Bentsen et al. (2012), except for the ocean model NorESM1-M is to a large extent based on the fourth version of the Community Climate System Model (CCSM4) developed in the Community Earth System Model (CESM) project centred at the US National Center for Atmospheric Research (NCAR) in collaboration with many partners (Gent et al., 2011; Meehl et al., 2012). The ocean model in both versions of NorESM1 is a considerably elaborated version of the Miami Isopycnic Community Ocean Model (MICOM) adapted for multi-century simulations in coupled mode by Assmann et al. (2010) and Otterå et al. (2010). Further extensions are described by Bentsen et al. (2012) together with a summary of all extensions since the original MICOM. The NorESM1 ocean model is predominantly developed at the Bjerknes Centre in Bergen, Norway, and an earlier version was also used in the Bergen Climate Model (BCM), which was used to provide data for CMIP3 (Meehl et al., 2005) and the AR4 of the IPCC (Furevik et al., 2003; Otterå et al., 2009). Important extensions since the BCM version include improved parameterisation of diapycnal mixing, isopycnal eddy diffusion, thickness eddy diffusion and the mixed layer depth.

The atmospheric model in NorESM1 (which denote both $\mathrm{M}$ and ME) is based on the version of the original CAM4 that was publicly released in April 2010 (Neale et al., 2010, 2012). Over the last $15 \mathrm{yr}$, research and modelling groups at the University of Oslo and the Norwegian Meteorological Institute (also in Oslo) have used a range of earlier NCAR model versions to develop representations of aerosols and their interactions with radiation and warm cloud microphysics. The purpose was to quantify the direct and indirect aerosol forcing (Iversen and Seland, 2002, 2003; Kirkevåg and Iversen, 2002; Kristjànsson, 2002; Storelvmo et al., 2006; Seland et al., 2008; Hoose et al., 2009; Struthers, et al., 2011) and to study aerosol interactions with climate (Kristjánsson et al., 2005; Kirkevåg et al., 2008a, b; Struthers et al., 2013). In these earlier studies of the climate response to aerosol processes, however, the atmospheric model was run coupled to a slab ocean model only. In NorESM1 the climate response of the aerosol processes is estimated in a fully coupled climate/earth system model. The latest version of the aerosol module, which is used in NorESM1, is thoroughly presented and discussed by Kirkevåg et al. (2013), and the CAM4-version with this aerosol module is denoted CAM4-Oslo.

We use the finite volume dynamical core for transport calculations (Rasch et al., 2006) with horizontal resolution $1.9^{\circ}$ latitude by $2.5^{\circ}$ longitude (in short: $2^{\circ}$ ) and 26 levels with a hybrid sigma-pressure co-ordinate in the vertical. The horizontal grid mesh size is double of the standard version used in CCSM4, although Gent et al. (2011) also discuss a $2^{\circ}$ version. The stratiform cloud parameterisation is based on Rasch and Kristjansson (1998), and the parameterisation of deep convective clouds follows Zhang and McFarlane (1995) extended with the plume dilution and convective momentum transport which is also used in CCSM4 (Richter and Rasch, 2007; Neale et al., 2008). Plume dilution influences the vertical distribution of aerosols (Kirkevåg et al., 2013) and water vapour (Gent et al., 2011), and improves the modelling of tropical deep convection in a way which turns out favourably for reproducing characteristic features of the Madden-Julian Oscillation (MJO) (Subramanian et al., 
2011). The favourable MJO properties are also diagnosed for NorESM1-M by Bentsen et al. (2012). NorESM1-M accounts for the radiative effects of deposited light-absorbing mineral dust and black carbon on snow (Flanner and Zender, 2006) and sea-ice.

A schematic of the CMIP5-experiments with NorESM1-M is shown by Bentsen et al. (2012) in their Fig. 1. Throughout this paper, we use "piControl" to identify the $500 \mathrm{yr}$ control simulation with constant external forcing prescribed at 1850 conditions. This simulation starts in year 700 after a spin-up with the same forcing. As discussed by Bentsen et al. (2012), the spin-up is carried out in order to reduce trends in the piControl after tuning of parameters. Three ensemble members were branched off from the piControl in years 700,730 and 760 for simulations "Historic1, "Historic2" and "Historic3". From 1850 to 2005, the natural variations of solar radiation (Lean et al., 2005; Wang et al., 2005), the stratospheric sulphate aerosol concentrations from explosive volcanoes (Ammann et al., 2003), and the anthropogenic changes in GHG concentrations, aerosol emissions (Lamarque et al., 2010) and land-cover, were prescribed using the data from http://cmip-pcmdi.llnl.gov/cmip5/forcing.html.

The historical forcing experiments branch off from piControl in year 700 as for Historic1. They are denoted "GHG only", "Aerosol only", and "Natural forcing only", where the forcing is kept constant as in piControl except for the single forcing contribution which is identified by the name. From 2005 onwards, the representative concentration pathway (RCP) scenarios (van Vuuren et al., 2011) were the basis for climate projections until 2100: RCP2.6, RCP4.5, RCP6.0 and RCP8.5, where the numbers are the expected TOA forcing in $\mathrm{Wm}^{-2}$ by 2100 . The RCP4.5 was extended to run until 2300 keeping external conditions as in 2100 . The historical simulations have been extended to 2012 using RCP8.5 for the years 2006-2012.

Bentsen et al. (2012) present a thorough validation analysis of trends in piControl along with comparisons of the historical runs with data that are observationally based or from global re-analyses. In summary, the average radiative heat flux at the top of the atmosphere (TOA) in piControl is positive, but smaller than $0.1 \mathrm{Wm}^{-2}$. More than $99 \%$ of this excess heat is transferred to the oceans, which experience a statistically significant temperature increase. There are also small negative trends in the ocean salinity, the winter maximum sea-ice area in both hemispheres and the Atlantic meridional overturning circulation (AMOC). Other climatologically important parameters have insignificant global trends during the $500 \mathrm{yr}$ of the piControl, including surface air temperature, cloudiness, precipitation and evaporation. The difference between global evapotranspiration and precipitation $(E-P)$ averaged over a few decades or longer, is not significantly different from zero in any of the experiments, including piControl, implying that the global water cycle budget in NorESM1-M is closed.
In summary from Bentsen et al. (2012), by the end of the 20th century the surface air temperature is simulated to be too low by about $0.8-0.9 \mathrm{~K}$ globally and $1.0-1.1 \mathrm{~K}$ over land. The global precipitation is estimated to be up to about $0.15 \mathrm{~mm} \mathrm{day}^{-1}$ too high, the evaporation from oceans is over-estimated with ca. $4 \%$, and the net flux between oceans and continents are ca. $8 \%$ over-estimated. The intensity of the water-cycle is, therefore, slightly overestimated, while the atmospheric lifetime of water vapour is close to correct (compared to Trenberth et al., 2011). These properties can be linked to the fact that the model underestimates the global cloud fraction considerably (by 15-25\%), while the tropospheric liquid water is over-estimated (Jiang et al., 2012). The double ITCZ is less pronounced in NorESM1-M than in CCSM4 with the same resolution.

The model simulates characteristic flow patterns that can be associated with features diagnosed from observational data. This includes the Madden-Julian Oscillation (MJO), which was simulated with skill already in CCSM4 (Subramanian et al., 2011), ENSO, and the northern and southern annular modes. The AMOC strength is in the upper range found in models contributing to CMIP3 and above the range estimated from synthesized observational data (Medhaug and Furevik, 2011). Whilst the sea-ice extent is overestimated in both hemispheres in summer and in the southern winter, it is underestimated during northern winter. Kirkevåg et al. (2013) used NorESM's atmospheric model CAM4-Oslo to estimate the direct and indirect forcing of aerosol changes between the years 1850 and 2000 (2006) to be $-0.10(-0.08)$ and $-0.91 \mathrm{Wm}^{-2}\left(-1.2 \mathrm{Wm}^{-2}\right)$, respectively. The estimated indirect forcing in warm clouds is modest compared to many other models, and this is achieved without assuming artificial lower thresholds in the number of aerosols or cloud droplets (Hoose et al., 2009). However, the modelled aerosol loadings are at the high end in the free troposphere (Myhre et al., 2013; Samset et al., 2013).

\section{Equilibrium climate sensitivity and transient response}

Global climate models are useful for diagnosing a range of characteristics for how the global climate may respond to a standard specified forcing. This facilitates the comparison of climate change properties across different climate models. This section discusses results of two such experiments under the CMIP5 protocol using NorESM1-M integrated over 150 and $140 \mathrm{yr}$, respectively. The simulations were both initiated in year 700 , i.e., from the start of piControl after spin-up, and are referred to as "abrupt $4 \times \mathrm{CO}_{2}$ " (quadrupling of atmospheric $\mathrm{CO}_{2}$ concentrations at $t=0$ ) and "gradual $4 \times \mathrm{CO}_{2}$ " (1\% increase per year until quadrupling). Results are presented in Tables 1, 2, 3 and 4, as well as in Fig. 1. Since we have not applied any proper method for estimating changes in single climate elements (e.g., cloud cover) in response 
Table 1. Different estimates of climate sensitivity of the NorESM1-M with $2^{\circ}$ resolution. Data for the CCSM 4 with $1^{\circ}$ resolution included for comparison are provided by Bitz et al. (2012). Symbols are explained in the main text; see also Fig. 1.

\begin{tabular}{|c|c|c|c|c|c|c|c|}
\hline & $\begin{array}{c}\Delta T_{\mathrm{eq}} \\
\mathrm{K}\end{array}$ & $\begin{array}{c}\Delta T_{\text {eff }} \\
\mathrm{K}\end{array}$ & $\begin{array}{c}\Delta T_{\text {reg }} \\
\quad \mathrm{K}\end{array}$ & $\begin{array}{c}R_{\mathrm{f}_{\text {reg }}} \\
\mathrm{Wm}^{-2}\end{array}$ & $\begin{array}{c}\lambda_{\text {reg }} \\
\mathrm{Wm}^{-2} \mathrm{~K}^{-1}\end{array}$ & $\begin{array}{c}\Delta T_{\mathrm{TCR}} \\
\mathrm{K}\end{array}$ & $\begin{array}{c}\Delta T_{\mathrm{TCR}, \mathrm{eff}} \\
\mathrm{K}\end{array}$ \\
\hline NorESM1-M, $2^{\circ}$ & not calc. & 2.86 & 2.87 & 3.16 & 1.101 & 1.39 & 2.32 \\
\hline CCSM $4,1^{\circ}$ & 3.20 & 2.78 & 2.80 & 2.95 & 1.053 & 1.72 & 2.64 \\
\hline
\end{tabular}

Table 2. Global gross feedback response $\left(\lambda_{X}\right)$ in TOA radiation parameters $(X)$ as determined by linear regression of model simulated annual change $(\Delta X)$ with respect to the corresponding annual surface air temperature change $(\Delta T)$ after abrupt $4 \times \mathrm{CO}_{2}$. The quantity $\lambda_{X}=\mathrm{d}(\Delta X) / \mathrm{d}(\Delta T)$, and $X$ is long-wave (LW) and short-wave (SW) all-sky and clear-sky TOA outgoing radiation, long-wave (LWCF) and short-wave (SWCF) cloud forcing, or net cloud radiative effect (CRE).

\begin{tabular}{cccccccc}
\hline & $\begin{array}{c}\lambda_{\text {LWAllsky }} \\
\mathrm{Wm}^{-2} \mathrm{~K}^{-1}\end{array}$ & $\begin{array}{c}\lambda_{\text {SWAllsky }} \\
\mathrm{Wm}^{-2} \mathrm{~K}^{-1}\end{array}$ & $\begin{array}{c}\lambda_{\text {LWclearsky }} \\
\mathrm{Wm}^{-2} \mathrm{~K}^{-1}\end{array}$ & $\begin{array}{c}\lambda_{\text {SWclearsky }} \\
\mathrm{Wm}^{-2} \mathrm{~K}^{-1}\end{array}$ & $\begin{array}{c}\lambda_{\mathrm{LWCF}} \\
\mathrm{Wm}^{-2} \mathrm{~K}^{-1}\end{array}$ & $\begin{array}{c}\lambda_{\text {SWCF }} \\
\mathrm{Wm}^{-2} \mathrm{~K}^{-1}\end{array}$ & $\begin{array}{c}\lambda_{\mathrm{CRE}} \\
\mathrm{Wm}^{-2} \mathrm{~K}^{-1}\end{array}$ \\
\hline NorESM1-M, $2^{\circ}$ & -1.80 & +0.70 & -1.86 & +0.84 & +0.06 & -0.15 & -0.09 \\
\hline
\end{tabular}

Table 3. Global gross feedback response $\left(\lambda_{X}\right)$ in parameters $(X)$ characterising the hydro-climate, as determined by linear regression of model simulated annual change $(\Delta X)$ with respect to the corresponding annual surface air temperature change $(\Delta T)$ after abrupt $4 \times \mathrm{CO}_{2} . X$ is annual amounts of evaporation $(E)$, precipitation $(P)$, or the difference $(E-P)$ accumulated globally, from oceans, or from land $\left(10^{3} \mathrm{~km}^{3} \mathrm{yr}^{-1}\right)$.

\begin{tabular}{ccccccc}
\hline & $\begin{array}{c}\lambda_{P-\mathrm{GLOB}} \\
10^{3} \mathrm{~km}^{3} \mathrm{~K}^{-1}\end{array}$ & $\begin{array}{c}\lambda_{\mathrm{E}-\mathrm{OCEAN}} \\
10^{3} \mathrm{~km}^{3} \mathrm{~K}^{-1}\end{array}$ & $\begin{array}{c}\lambda_{P \text {-OCEAN }} \\
10^{3} \mathrm{~km}^{3} \mathrm{~K}^{-1}\end{array}$ & $\begin{array}{c}\lambda_{(E-P) \text {-OCEAN }} \\
10^{3} \mathrm{~km}^{3} \mathrm{~K}^{-1}\end{array}$ & $\begin{array}{c}\lambda_{E-L A N D} \\
10^{3} \mathrm{~km}^{3} \mathrm{~K}^{-1}\end{array}$ & $\begin{array}{c}\lambda_{P-\mathrm{LAND}} \\
10^{3} \mathrm{~km}^{3} \mathrm{~K}^{-1}\end{array}$ \\
\hline NorESM1-M, $2^{\circ}$ & 14.58 & 12.42 & 12.40 & $\begin{array}{c}+0.02 \\
(-0.29-+0.32)\end{array}$ & 2.16 & 2.18 \\
\hline
\end{tabular}

Table 4. Global gross feedback response $\left(\lambda_{X}\right)$ in $(X=)$ yearly averaged sea-ice area (AREA, $10^{6} \mathrm{~km}^{2} \mathrm{yr}^{-1}$ ), and volume $(\mathrm{VOL}$, $10^{3} \mathrm{~km}^{3} \mathrm{yr}^{-1}$ ) in the Northern (NH) or Southern ( $\left.\mathrm{SH}\right)$ Hemispheres, as determined by linear regression of model simulated annual change $(\Delta X)$ with respect to the corresponding annual surface air temperature change $(\Delta T)$ after abrupt $4 \times \mathrm{CO}_{2}$.

\begin{tabular}{ccccc}
\hline & $\begin{array}{c}\lambda \text { AREA-NH } \\
10^{6} \mathrm{~km}^{2} \mathrm{~K}^{-1} \mathrm{yr}^{-1}\end{array}$ & $\begin{array}{c}\lambda \text { VOL-NH } \\
10^{3} \mathrm{~km}^{3} \mathrm{~K}^{-1} \mathrm{yr}^{-1}\end{array}$ & $\begin{array}{c}\lambda_{\mathrm{AREA}-\mathrm{SH}} \\
10^{6} \mathrm{~km}^{2} \mathrm{~K}^{-1} \mathrm{yr}^{-1}\end{array}$ & $\begin{array}{c}\lambda_{\text {VOL-SH }} \\
10^{3} \mathrm{~km}^{3} \mathrm{~K}^{-1} \mathrm{yr}^{-1}\end{array}$ \\
\hline NorESM1-M, $2^{\circ}$ & -2.39 & -10.55 & -0.86 & -2.52 \\
\hline
\end{tabular}

to temperature increases when other elements are kept unchanged, the feedback factors we present (e.g., for clouds) are termed gross feedback factors (Andrews et al., 2012). These factors can be influenced by simultaneous changes in other elements than the temperature (e.g., snow cover). See Gettelman et al. (2012) for estimates of proper feedback factors.

The Equilibrium Climate Sensitivity (ECS) is defined as the change in global mean near-surface air temperature when a new climate equilibrium is reached after an abrupt increase of the atmospheric $\mathrm{CO}_{2}$ concentrations introduced to a climate already in equilibrium. To calculate the ECS from first principles requires climate model simulations over several thousand years (Boer and Yu, 2003). ECS is, therefore, frequently approximated as the difference, $\Delta T_{\mathrm{eq}}$, between equilibrium near surface air temperatures obtained from two runs over a few decades, but with a model version where the deep ocean model is replaced by a thermodynamic slab. Bitz et al. (2012) used a slab ocean model for which the deep ocean heat fluxes were calibrated with data from runs with the full CCSM4. With $1^{\circ}$ atmospheric resolution they estimated $\Delta T_{\text {eq }}=3.20 \mathrm{~K}$ after doubling of $\mathrm{CO}_{2}$, while $3.13 \mathrm{~K}$ was estimated for the $2^{\circ}$ version. This is close to the value $3.14 \mathrm{~K}$ which was found for the previous CAM3-based version of CAM-Oslo coupled to a slab ocean (Kirkevåg et al., 2008a).

Estimates of $\Delta T_{\mathrm{eq}}$ for NorESM1-M with a slab ocean are not available, but two other approximations of ECS are estimated for the full NorESM1-M. Both methods use simultaneous values of surface air temperature change $(\Delta T(t))$ and TOA radiation imbalance $(\Delta R(t))$ estimated at the time 
$t$ after the abrupt quadrupling of atmospheric $\mathrm{CO}_{2}$ concentrations.

Gregory et al. (2004) proposed to use a linear regression between $\Delta R(t)$ and $\Delta T(t)$, assuming negligible contributions from time-varying feedbacks. The slope of the regression line is the overall feedback parameter $\lambda=-\mathrm{d} \Delta R / \mathrm{d} \Delta T$ (in units of $\mathrm{Wm}^{-2} \mathrm{~K}^{-1}$ ), the intercept at $\Delta T=0$ approximates the instantaneous forcing $R_{\mathrm{f}}$, while the intercept $\Delta T_{\text {reg }}$ at $\Delta R=0$ approximates the ECS. In reality, this estimate of $R_{\mathrm{f}}$ disregards rapid adjustments during the first year of the simulation and it, therefore, underestimates the true instantaneous forcing of the quadrupled $\mathrm{CO}_{2}$ (Andrews et al., 2012).

Murphy (1995) proposed to use the remaining TOA radiative imbalance $\Delta R(t)$ at the time $t$ to approximate ECS. This approximation, termed the effective climate sensitivity and denoted $\Delta T_{\mathrm{eff}}(t)$, is:

$\Delta T_{\mathrm{eff}}(t)=\frac{\Delta T(t) R_{\mathrm{f}}}{R_{\mathrm{f}}-\Delta R(t)}$.

Assuming the same linear relationship between $\Delta T(t)$ and $\Delta R(t), \Delta T_{\text {eff }}$ should not depend on time. However, slow feedback processes, for example involving the deep ocean, may cause changes to occur over decades and centuries (Senior and Mitchell, 2000). Furthermore, chaotic fluctuations in the climate response may lead to high-frequency variations in $\Delta R(t)$. Figure 1a shows results for both $\Delta T(t)$ (black dots for years 1-150) and $\Delta T_{\text {eff }}$ (red dots for years 111-150), where we assume $R_{\mathrm{f}}=7.0 \mathrm{Wm}^{-2}$ as estimated by Kay et al. (2012).

The two approximations to ECS are $\Delta T_{\text {reg }}\left(4 \times \mathrm{CO}_{2}\right)=$ $5.74 \mathrm{~K}$ from the regression, with feedback parameter $\lambda \cong 1.101 \mathrm{Wm}^{-2} \mathrm{~K}^{-1}$, and $\Delta T_{\text {eff }}\left(4 \times \mathrm{CO}_{2}\right)=5.71 \mathrm{~K}$ using Eq. (1) with values averaged over the last 40 of the $150 \mathrm{yr}$ of the abrupt $4 \times \mathrm{CO}_{2}$ experiment (black cross in Fig. 1). The numbers in Table 1 are these divided by 2 since the effect of $\mathrm{CO}_{2}$ doubling are more standard in the literature (e.g., Andrews et al., 2012). Notice that the forcing approximated by the regression (see Fig. 1a) is only $6.32 \mathrm{Wm}^{-2}$ due to the fast adjustments during the first year of the integration. Furthermore, slow deep-oceanic feedbacks may delay the response and, thus, render the linear regression inaccurate. For example, a regression for years 1-76 yields a smaller approximation of the ECS $(5.18 \mathrm{~K})$, indicating that there may be slow feedback mechanisms at work. Andrews et al. (2012) indicate that short-wave radiative effects of clouds over oceans may cause nonlinearity over the first decades.

As shown in Table 1, our approximate ECS estimates for doubled $\mathrm{CO}_{2}$ are close, but slightly larger than Bitz et al. (2012) obtained for CCSM4. For both NorESM1-M and CCSM4, the estimates of $\Delta T_{\text {reg }}$ are in close agreement with the estimated $\Delta T_{\text {eff. }}$ In relation to the other 14 models studied by Andrews et al. (2012) NorESM1-M is amongst the least sensitive. Figure $1 \mathrm{~b}$ and the numbers in Table 2 show that clouds tend to stabilise the response as the long-wave response is positive but small, and the short-wave response is negative. Of the 15 models studied by Andrews et al. (2012), 9 produce a negative gross cloud feedback, and the spread in values are large. NorESM1-M is close to the average. There is a much better agreement between models for clearair feedback, all with values close to those given in Table 2 (Andrews et al., 2012).

A simple measure of climate sensitivity associated with gradual changes in the external forcing is the Transient Climate Response (TCR). TCR can be estimated from the gradual $4 \times \mathrm{CO}_{2}$ experiment as the globally averaged difference in surface air temperature $\left(\Delta T_{\mathrm{TCR}}\right)$ between the time of doubled atmospheric $\mathrm{CO}_{2}$ (averaged over years 60-80) and the corresponding years in the piControl. An effective response that approximately takes into account the remaining TOA radiative imbalance can also be estimated by applying Eq. (1). We have estimated $\Delta T_{\mathrm{TCR}}$ to be $1.39 \mathrm{~K}$ and $\Delta T_{\mathrm{TCR} \text {,eff }}$ to be $2.32 \mathrm{~K}$, and compared them with values calculated for CCSM4 by Bitz et al. (2012) (Table 1). While the approximate values for ECS were close to each other, the TCR for NorESM1-M is considerably smaller than for CCSM4. As discussed below, this feature of the TCR for NorESM1$\mathrm{M}$ can be related to the model's strong AMOC which contributes to an efficient flux of heat into the oceans.

As documented by Bentsen et al. (2012), the average maximum strength of the AMOC at $26.5^{\circ} \mathrm{N}$ in piControl is $30.8 \mathrm{~Sv}\left(\mathrm{~Sv}=10^{6} \mathrm{~m}^{3} \mathrm{~s}^{-1}\right)$. Gent et al. (2011) reports the maximum AMOC strength in CCSM4 to be above $24 \mathrm{~Sv}$, which is also strong compared to many other models. Figure 1c shows how AMOC responds to the abrupt (blue) and gradual (red) $\mathrm{CO}_{2}$ increase in the model, and Fig. 1d shows, for the gradual $4 \times \mathrm{CO}_{2}$ experiment, that the deep ocean is particularly efficiently heated at high latitudes where dense water is created and sinks. While AMOC is reduced by $8-10 \mathrm{~Sv}$ over the first couple of decades and then remains almost constant in the abrupt experiment, the reduction is slower and almost linear with time in the gradual experiment. Figure 1e and $f$ show the heat flux at different ocean depths averaged over the entire globe and illustrates how efficient the net downward radiative heat flux at the top of the model penetrates downwards in the world oceans.

By the time of $\mathrm{CO}_{2}$ doubling, AMOC is reduced with about 3-5 Sv in the gradual experiment. The heat fluxes into the deep ocean shown in Fig. 1e and $f$ reduce the fraction of the net heat flux at the top of the model that is available for further increase in surface temperatures, evaporation of water and melting of ice. An efficient heat transport into the deep oceans, thus, reduces the traditional measures of climate sensitivity. It can be seen from Fig. If that a slab ocean model with $200 \mathrm{~m}$ thickness of the mixed layer would require almost $50 \mathrm{yr}$ spin-up to reach a quasi-equilibrium state for the $4 \times \mathrm{CO}_{2}$ climate. The transfer of heat into the deep ocean is a much slower and spatially heterogeneous process.

Despite that AMOC is stronger in the experiment with gradual $\mathrm{CO}_{2}$-increase, the heat transport into the deep ocean may appear more efficient in the abrupt experiment. This is 

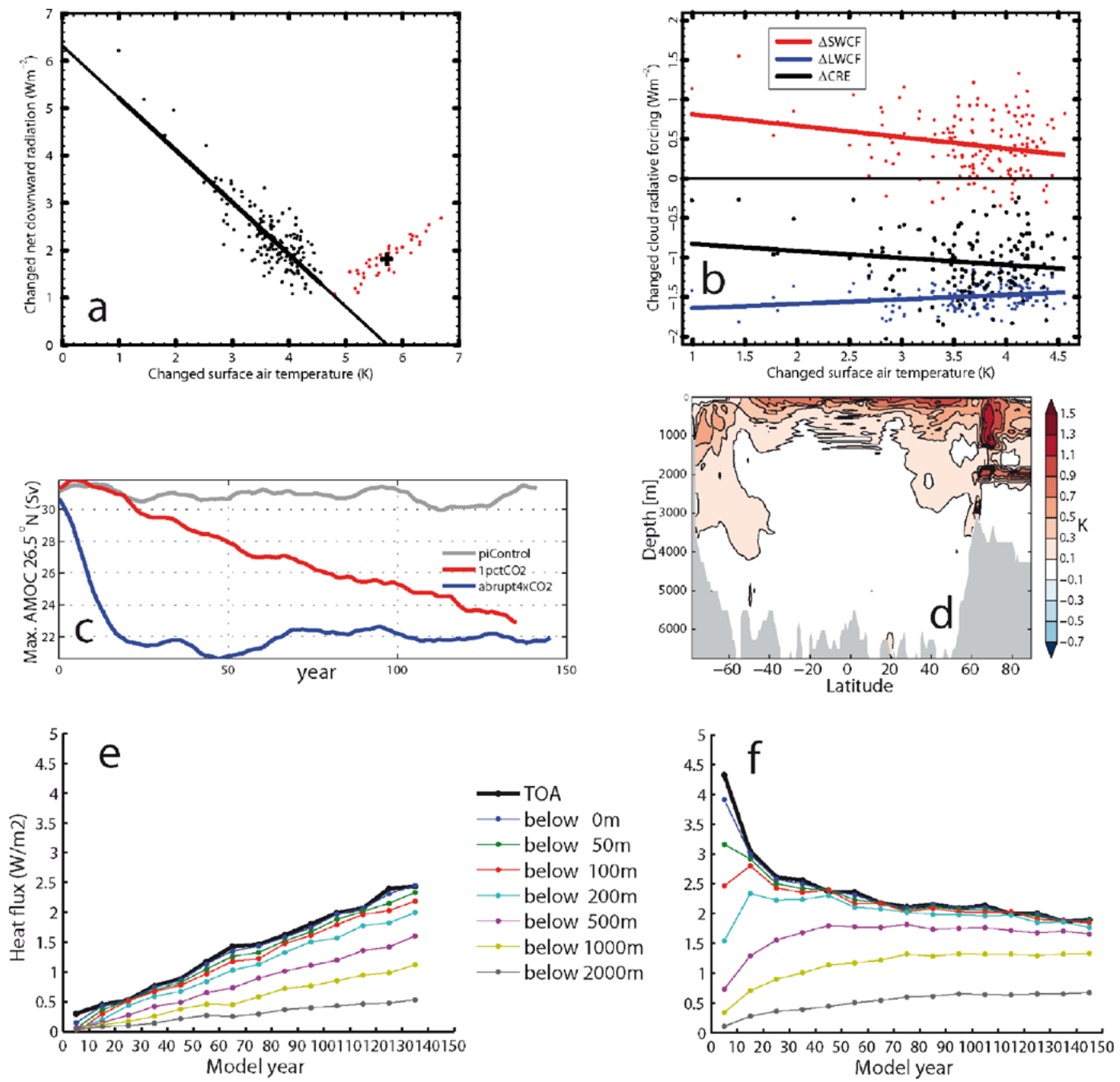

Fig. 1. Aspects of climate sensitivity and gross feedback effects in NorESM1-M based on the experiments "abrupt $4 \times \mathrm{CO}_{2}$ " and "gradual $4 \times \mathrm{CO}_{2}$ ". (a) Model simulated change in yearly TOA net downward radiation $\left(\mathrm{Wm}^{-2}\right)$ as a function of changed global surface air temperature (K) (black dots) and effective temperature response, $\Delta T_{\text {eff }}(n)$ (red dots, $n=111, \ldots, 150$ ), for the abrupt $4 \times \mathrm{CO}_{2}$ experiment. The black line is the linear regression with a slope $\lambda=1.101 \mathrm{Wm}^{-2} \mathrm{~K}^{-1}$ and intercept $\Delta T_{\mathrm{reg}}\left(4 \times \mathrm{CO}_{2}\right)=5.74 \mathrm{~K}$ with the x-axis. The black cross is the average for the red dots with $\Delta T_{\text {eff }}\left(4 \times \mathrm{CO}_{2}\right)=5.71 \mathrm{~K}$. (b) Calculated changes in TOA long wave (blue), short wave (red) and net (black) downward cloud radiation $\left(\mathrm{Wm}^{-2}\right)$, as a function of changed global surface air temperature for the abrupt $4 \times \mathrm{CO}_{2}$ experiment. The slopes of the linear regression lines are given in Table 2. (c) The maximum AMOC (Sv) at $26.5^{\circ} \mathrm{N}$ as a function of time for piControl (grey), abrupt $4 \times \mathrm{CO}_{2}$ (blue) and gradual $4 \times \mathrm{CO}_{2}$ (red). (d) Changed temperature zonally averaged for global oceans for the gradual $4 \times \mathrm{CO}_{2}$ experiment at the time of $\mathrm{CO}_{2}$ doubling. (e) The global TOA radiation heat flux as a function of time in the gradual $4 \times \mathrm{CO}_{2}$ experiment along with the globally averaged downward flux of heat through depth levels in the world oceans. (f) Same as (e), but for the abrupt $4 \times \mathrm{CO}_{2}$ experiment.

an artefact caused by the exponential increase in atmospheric $\mathrm{CO}_{2}$ (1\% increase per year) starting from pre-industrial levels. These annual forcing increments add to the TOA imbalance, and the increments penetrate into the deep ocean with a characteristic time which is influenced by the strength of the AMOC. As the AMOC strength decreases gradually, the downward heat transport at high latitudes also decreases. The deep ocean heating will, therefore, continue several decades even without further $\mathrm{CO}_{2}$ increase after the doubling (when the TCR is estimated), but the efficiency will gradually decrease as AMOC steadily reduces its strength before stabilising at a smaller value. This is due to the heating and freshening of the upper ocean layers at high latitudes. This slow reduction of the deep ocean heating efficiency is different from the abrupt experiment which establishes a new quasi-stable AMOC already after a few decades. We hypothesise that $\Delta T_{\mathrm{TCR}, \text { eff }}$ at the time of $\mathrm{CO}_{2}$-doubling underestimates the true equilibrium temperature after $\mathrm{CO}_{2}$-doubling, due to this multi-decadal nonlinear contribution to the feedbacks. 
The results from linear regressions between corresponding changes in selected variables characterising the global climate and the change in surface air temperature for the abrupt $4 \times \mathrm{CO}_{2}$ experiment, are summarised in Tables 3 and 4 . Table 3 shows positive gross feedback factors for the hydroclimatic variables, i.e., how much they change with a unit (K) increase in temperature. The factor for global precipitation increase is equivalent to ca. $2.7 \% \mathrm{~K}^{-1}$, which probably is on the high side (e.g., Trenberth, 2011). The factor is about 6 times larger over the oceans than over continents, but almost all of the response over the ocean is due to recycling of oceanic evaporation. The slight surplus of $0.02 \times 10^{3} \mathrm{~km}^{3} \mathrm{~K}^{-1}$ for oceanic evaporation over precipitation equals the deficit over the continents. This number results from a small imbalance between terms that are several orders of magnitude larger, and the implied uncertainty is shown as an interval in Table 3. Nevertheless, based on the abrupt $4 \times \mathrm{CO}_{2}$ experiment, the model predicts a more intense water cycle with a small, but uncertain increase in the atmospheric lifetime of water vapour with increased temperatures.

Corresponding factors for change in yearly mean sea-ice volume and area in each of the hemispheres are given in Table 4 . The sensitivity parameters are all negative and the sensitivity is considerably higher in the Arctic than in the Antarctic. In the Arctic, melting of sea-ice is in particular associated with the surface albedo feedback effect, which also involves changes in the snow cover.

\section{Time trends of interactive forcing agents}

The only prescribed aerosol concentrations in the model are stratospheric sulphate from explosive volcanoes in the historical period (Ammann et al., 2003). Other aerosol components are calculated from prescribed emission data, or, for sea-salt, from emissions calculated as a function of wind speed and ocean temperature. Kirkevåg et al. (2013) present and evaluate the aerosol module, including estimates of direct and indirect aerosol forcing. We emphasise that a correct simulation of forcing of anthropogenic aerosols since 1850 depends on the amount and properties of the background of aerosols in 1850 of natural and anthropogenic (biomass burning and early industrialisation) origins, as well as the associated cloud droplet properties (Hoose et al., 2009). It should be noted that there were considerable anthropogenic aerosols already in 1850. In a few places, emissions from forest fires and also from natural secondary organics from areas that used to be forested were larger in 1850 . The model calculates mass concentrations of sulphate, black carbon (BC) and particulate organic matter (POM) which includes the secondary organics (SOA), in addition to the major natural components sea-salt and mineral dust. The aerosols interact directly with solar radiation, and a prognostic equation for the liquid water droplet number in stratiform clouds uses activation of cloud condensation nuclei $(\mathrm{CCN})$ from the modelled distribution of aerosol size and composition (Storelvmo et al., 2006).

Figure 2 shows the historic and future scenario developments of the average global loadings of particulate sulphate, BC, and POM since 1850 as simulated by NorESM1-M. Both natural and anthropogenic aerosols are included, but the major part of the long-term trends since 1850 are due to anthropogenic activities involving fossil fuel combustion and to some extent biomass burning. POM has a relatively larger fraction of natural aerosols because of biogenic emissions from oceans and from land vegetation. All the RCP scenarios, and RCP2.6 for $\mathrm{BC}$ in particular, peak during the first decades of the 21 st century before decaying to slightly higher levels than in 1850 towards the end of the century. The globally averaged aerosol optical depth and the absorption component both show the natural part in the historical period. They include the contribution of stratospheric sulphate from known explosive volcanoes since 1850, and the scattering effect of the volcanic aerosols is considerable for $1-3 \mathrm{yr}$ in each case. This also demonstrates that the sustained impacts of the anthropogenic aerosols are due to the continuous replenishment from human activity. The decaying loadings and optical depths in the 21 st century, therefore, follow immediately from assumed changes in emissions. For most greenhouse gases this is not the case, because of their long residence time in the earth system.

Figure 3 shows the calculated TOA long-wave, short-wave and net radiative imbalances in the period from 1850 to 2300 . While a negative trend is simulated for both the long-wave and short-wave from 1850 to 1970 , the net radiative flux has a trend close to zero. The trends become positive after ca. 1970 and increase for the future RCP scenarios. The net TOA imbalance is ca. $0.6 \mathrm{Wm}^{-2}$ by the first decade of the $21 \mathrm{st}$ century, but the year-to-year variations are substantial. The effect of the change after 1970 is seen in the global mean near surface temperature and in the global precipitation rate. Bentsen et al. (2012) discuss the realism of this and other results for the historical period.

\section{Historical single forcing simulations}

As an element in attributing climate change and variability since 1850 to possible causes, a few selected single forcing simulations are made as a part of the CMIP5 protocol. We have only run single realisations for each of these forcing simulations, which is insufficient to estimate statistical significance with respect to attribution of climate variations. However, they contribute to the multi-model ensemble in CMIP5 for IPCC AR5. Here we discuss three such experiments. In "GHG only", all but the prescribed greenhouse gas concentrations are kept constant at the 1850-level; in "Aerosol only" all but aerosol emissions are as in 1850; and in "Natural forcing only", only the natural contributions from solar activity and eruptive volcanoes are varied after 1850 . 

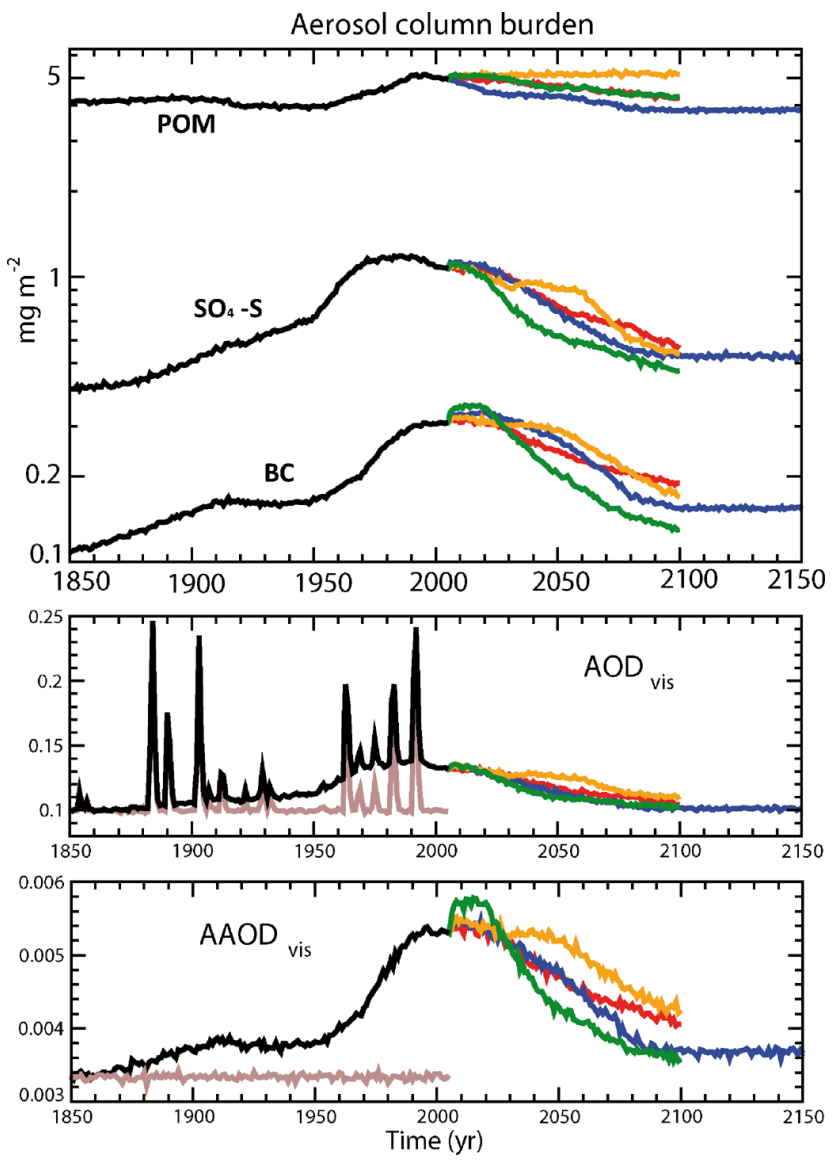

Fig. 2. Globally and annually averaged aerosol column burdens for particulate organic matter (POM), particulate sulphate as $\mathrm{S}\left(\mathrm{SO}_{4}-\mathrm{S}\right)$, and black carbon (BC) (upper panel), aerosol optical depth (AOD) (middle panel), and aerosol optical depth for absorption (AAOD) (lower panel) from 1850 onwards, calculated online in NorESM1M. Curves for Historic1 from 1850 to 2005 are black. For scenario projections, green are RCP2.6 for 2005-2100, blue are RCP4.5 for 2005-2300 (negligible variations after 2150), orange are RCP6.0 for 2005-2100, and red are RCP8.5 for 2005-2100. The brown curves are contributions to AOD and AAOD in Historic1 by natural aerosols only, including prescribed stratospheric sulphate from explosive volcanoes.

Figure 4 shows results for surface air temperature and precipitation in the individual forcing experiments. For temperature it appears that the simulated warming since the $1970 \mathrm{~s}$ cannot be reproduced with natural forcing only. Furthermore, the greenhouse gases alone will lead to an exaggerated warming estimate, while aerosols significantly dampen the warming exerted by GHG. For global precipitation the picture is much less clear, and the regional variations in the simulated precipitation changes are crucial. Even if the global trend in the annual precipitation is positive, there are considerable reductions in some continental regions.

The maps in Fig. 4 show that regional responses to GHG forcing and aerosol forcing have many similar geographical
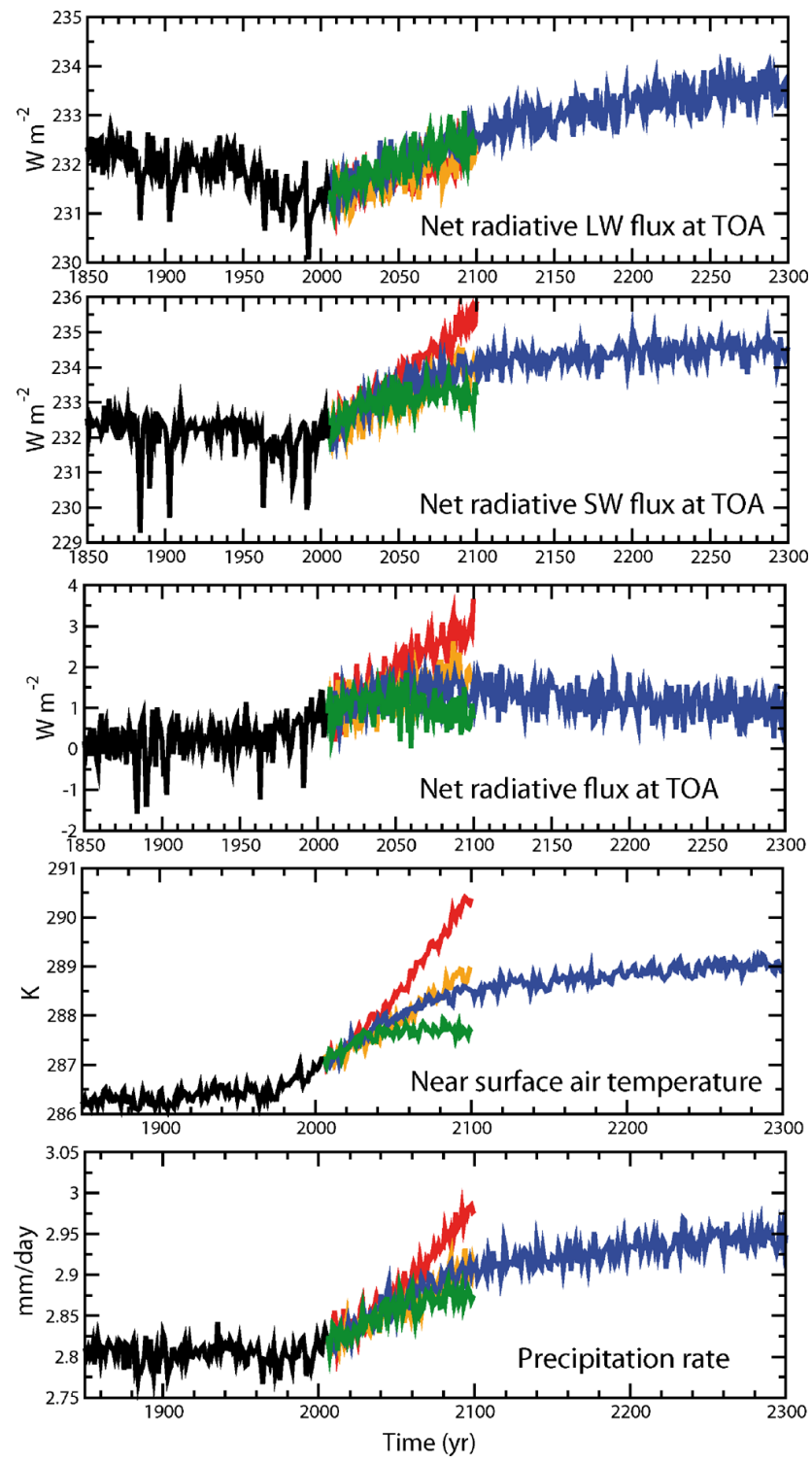

Fig. 3. From the top panel and downwards, the figure shows the net global long-wave (positive upwards), short-wave (positive downwards), and total (positive downwards) radiative flux at the top of the atmosphere during the NorESM1-M simulations for 1850 to 2300. The next two panels show diagrams for the global surface air temperature and average daily precipitation. Black: Historic1, green: RCP2.6, blue: RCP4.5, orange: RCP6.0, and red: RCP8.5.

patterns, but with opposite sign. Given that the spatial forcing patterns of GHG and aerosols are very different, the similarity in the response pattern demonstrates that internal dynamics (Palmer, 1999; Branstator and Selten, 2009) and geographically determined feedbacks (Boer and Yu, 2003) determine the nature of the climate response, rather than the forcing pattern itself. Kirkevåg et al. (2008b) found similar results with a model coupled to a slab ocean. 

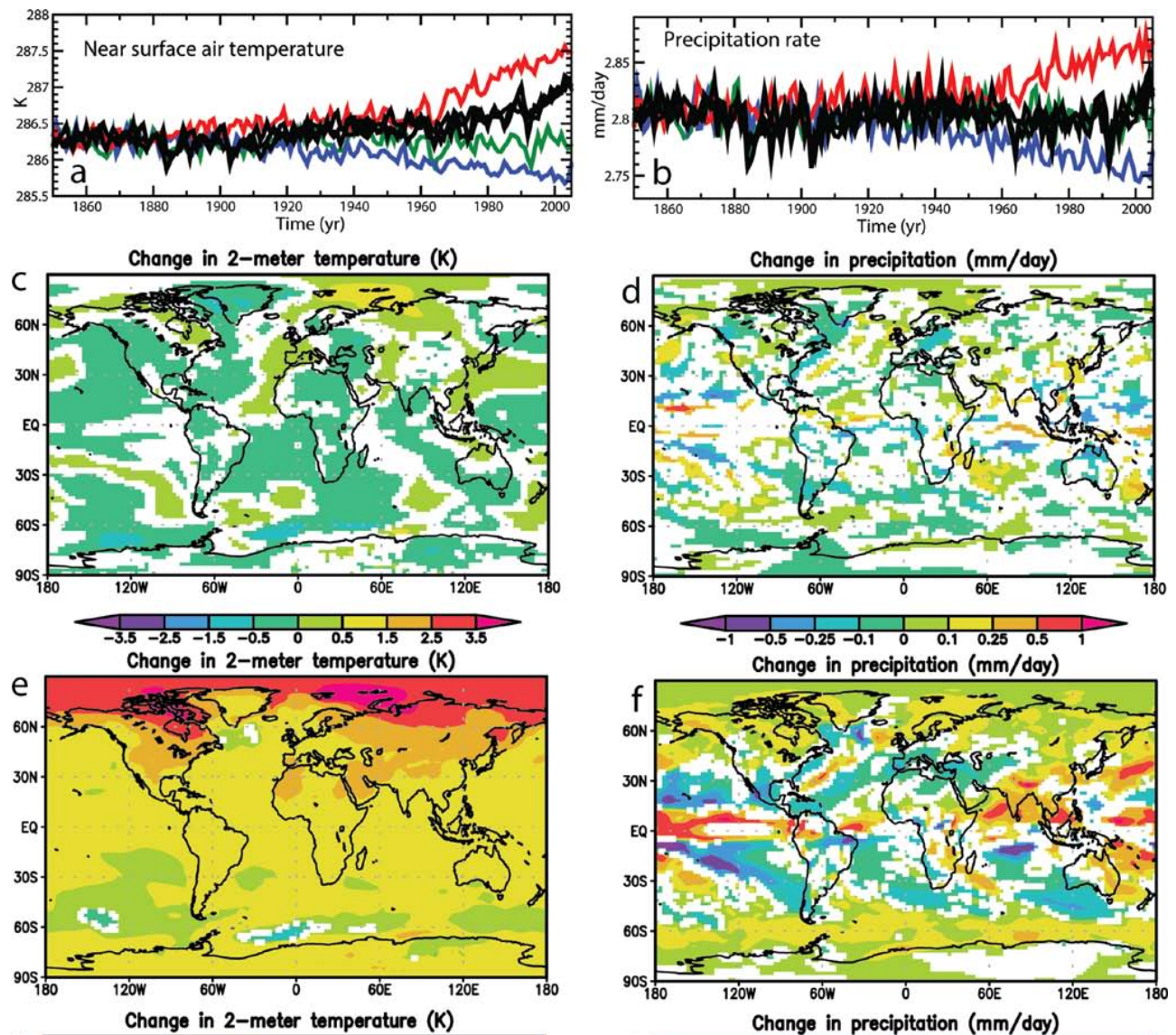

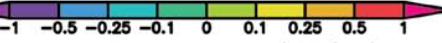

Change in precipitation ( $\mathrm{mm} / \mathrm{day}$ )
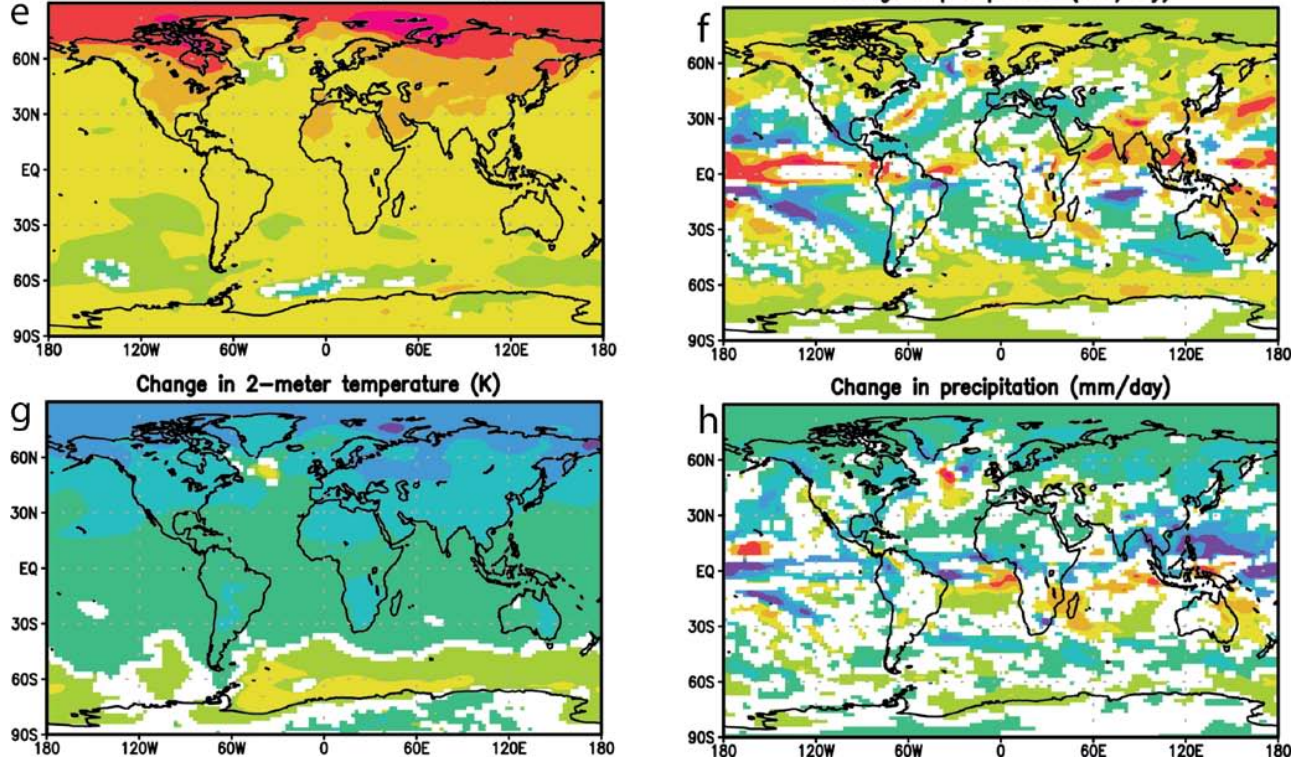

Fig. 4. NorESM1-M single forcing simulations of the historical period 1850-2005 and for the period 1976-2005 compared to piControl. Response in annual mean surface air temperature (left panels $\mathbf{a}, \mathbf{c}, \mathbf{e}, \mathbf{g}$ ) and average daily precipitation amounts (right panels, $\mathbf{b}, \mathbf{d}, \mathbf{f}, \mathbf{h}$ ). The graphs in the top panels (a and b) show global annual values from 1850 to 2005 for Historic1, 2, and 3 with full forcing (black), with natural forcing only (green), GHG-forcing only (red), and aerosol-forcing only (blue). The maps in the six panels below show changes between piControl and 1976-2005 for natural forcing only (c and d), GHG-forcing only (e and f), and aerosol forcing only (g and h). White patches indicate areas where changes are not significant at the $95 \%$ confidence level (two-sided, Student t-test with respect to variance of annual values in piControl).

Figure 4 also shows that there are only small and patchy regional changes of temperature and precipitation in the run with only natural forcing included. Even though regionally the changes are diagnosed as significant at $5 \%$ level compared to the unforced variance of annually averaged values, the trends appear unsystematic, where positive and negative values are approximately equally likely. This contrasts with the systematic trends in the runs with GHG-forcing only and aerosol-forcing only.
There are important exceptions for the precipitation response, however, which has the same sign for GHG forcing and aerosol forcing in some areas. This kind of apparent mutual reinforcement may occur by chance due to internal variability, and firm conclusions based on single realisations of the experiment are not possible. To some extent, random reinforcements or cancellations can be checked by adding the spatial response of each single forcing experiment and compare this sum with the response of a single experiment that employs the sum of the two forcing components. In areas 
where the two fields differ considerably, chaotic internal variations may dominate over systematic mutual reinforcements or cancellations. Since random patterns in the two singleforcing experiments may also behave similarly by chance, however, a more confident conclusion requires several ensemble members.

The maps in Fig. 5 show the added annual precipitation responses of the GHG-only and the aerosol-only (c) and its difference from the total response in the Historic1 run (d). The difference in Fig. 5d is influenced by chaotic internal variability as well as impacts of minor forcing agents originating from volcanic eruptions, and changes in solar activity and surface albedo due to changed land cover. Amongst these, only the impacts of the sum of volcanoes and solar activity (natural forcing) are investigated in separate CMIP5-runs for the historic period, and the sum of the response to those, GHG-only, and aerosols-only are shown in Fig. 5e, whilst Fig. 5f show the difference between that sum and Historic1. The minor differences between Fig. $5 \mathrm{~d}$ and $\mathrm{f}$ indicate that the differences in (d) are dominated by the sum of the response to land cover driven surface albedo changes and unforced, internal variability (chaos) and not by a response to the natural forcing. Unfortunately, we cannot quantify how large fraction of this is pure chaotic variability.

Any trend signals that, according to colours in Fig. 5c, may exist in areas that are not white in Fig. 5d are likely to be partly or fully masked by internal variability or land-cover induced albedo changes. On the other hand, areas which are white in both (c) and (d) probably experience systematically vanishing trends, for example due to cancellation between the effects of GHG and aerosols. Systematic non-zero trends are indicated where areas are coloured in (c) but white in (d), or the coloured values in (d) are considerably smaller than those in (c).

Based on this, the NorESM1-M results indicate significant increases in extra-tropical precipitation over oceans, whilst precipitation in sub-tropical areas and in some northern hemispheric continental temperate regions is reduced. In the tropics, vanishing precipitation trends dominate except for a few regions to the south (Africa and Oceania), where trends are positive.

The impact of GHG forcing on the tropical and subtropical precipitation patterns shown in Fig. 4 (right middle panel) relates to an intensified Hadley circulation with increased precipitation close to the equator and reduced in the adjacent subtropics in both hemispheres. The changes over oceans west of South America and Africa are not statistically significant at the $5 \%$ level. There are also extended dry zones towards the middle latitudes. Whilst the impacts of aerosols in general tend to counteract the GHG-driven changes at low latitudes (Fig. 4 lower right panel), the larger cooling by anthropogenic aerosols in the Northern than in the Southern Hemisphere leads to a southward displacement of the Hadley cell and the associated strong precipitation in the ITCZ. This result was reported, for example, by Rotstayn and
Lohmann (2002), Kristjansson et al. (2005), and Kirkevåg et al. (2008b) using slab ocean models. The reduced and displaced Hadley circulation caused by anthropogenic aerosols may lead to partial reinforcements of the considerably more symmetric strengthening caused by the GHG.

Since aerosols predominantly influence solar radiation, the asymmetric response is particularly pronounced during the NH summer. This can be seen by comparing Fig. 5a and $b$. The subtropical drying appears more pronounced in the Northern Hemisphere than in the Southern, while the moistening of the tropics is more pronounced in the southern flank of the ITCZ. As discussed in the companion paper by Bentsen et al. (2012), we relate the effects of aerosols to an improved precipitation pattern in NorESM1-M with a reduced split of the ITCZ over low latitudes in the Pacific Ocean compared to CCSM4 (Gent et al., 2011).

\section{Climate projections based on RCP-scenarios}

In accordance with the timing of the prescribed developments of concentrations and emissions in the RCP-scenarios, the first ensemble member of the historical period is extended with 4 climate projections to year 2100 . RCP4.5 is, furthermore, extended to year 2300. Results discussed here are given in Tables 5 and 6, and Figs. 6-10.

\subsection{Surface temperatures and sea-ice}

Figure 6 shows calculated surface air temperatures at reference height relative to the mean 1850-1899 averaged both globally and over the polar region north of $65^{\circ} \mathrm{N}$. By the end of the 21 st century, the global mean ranges from ca. $+1.2 \mathrm{~K}$ for RCP2.6 to ca. +4.0 K for RCP8.5 and the polar region mean from ca. $+3.5 \mathrm{~K}$ to $9.7 \mathrm{~K}$, with a notable downward trend for RCP2.6. The global numbers in Table 5 are smaller as they represent changes for two 30 -yr periods separated by $95 \mathrm{yr}$ (1976-2005 to 2071-2100).

The year-to-year variability is also considerably larger for the $\mathrm{NH}$ polar region than globally. The signal-to-noise ratio is not quantified, but it is smaller in the polar region due to the large natural variability in the region (Bentsen et al., 2012). Together with the fact that NorESM1-M underestimates the observed trends north of $60^{\circ} \mathrm{N}$, this hampers a firm conclusion concerning the quality of modelled climate trends in the Arctic.

Figure 7 shows a comparison of NorESM1-M surface air temperature relative to the $1850-1899$ average, with statistics from 15 CMIP5 models (one being NorESM1-M, Andrews et al., 2012). The selected results are for the RCP2.6 and RCP8.5 scenarios and are global means (left) and averages over land areas (right). NorESM1-M values are within one standard deviation away from the multi-model mean, but persistently lower than the average. This is in accordance with the relatively small climate sensitivity found in Sect. 3. A full explanation will require a separate study of the properties of all the models. Candidate explanations should for example 

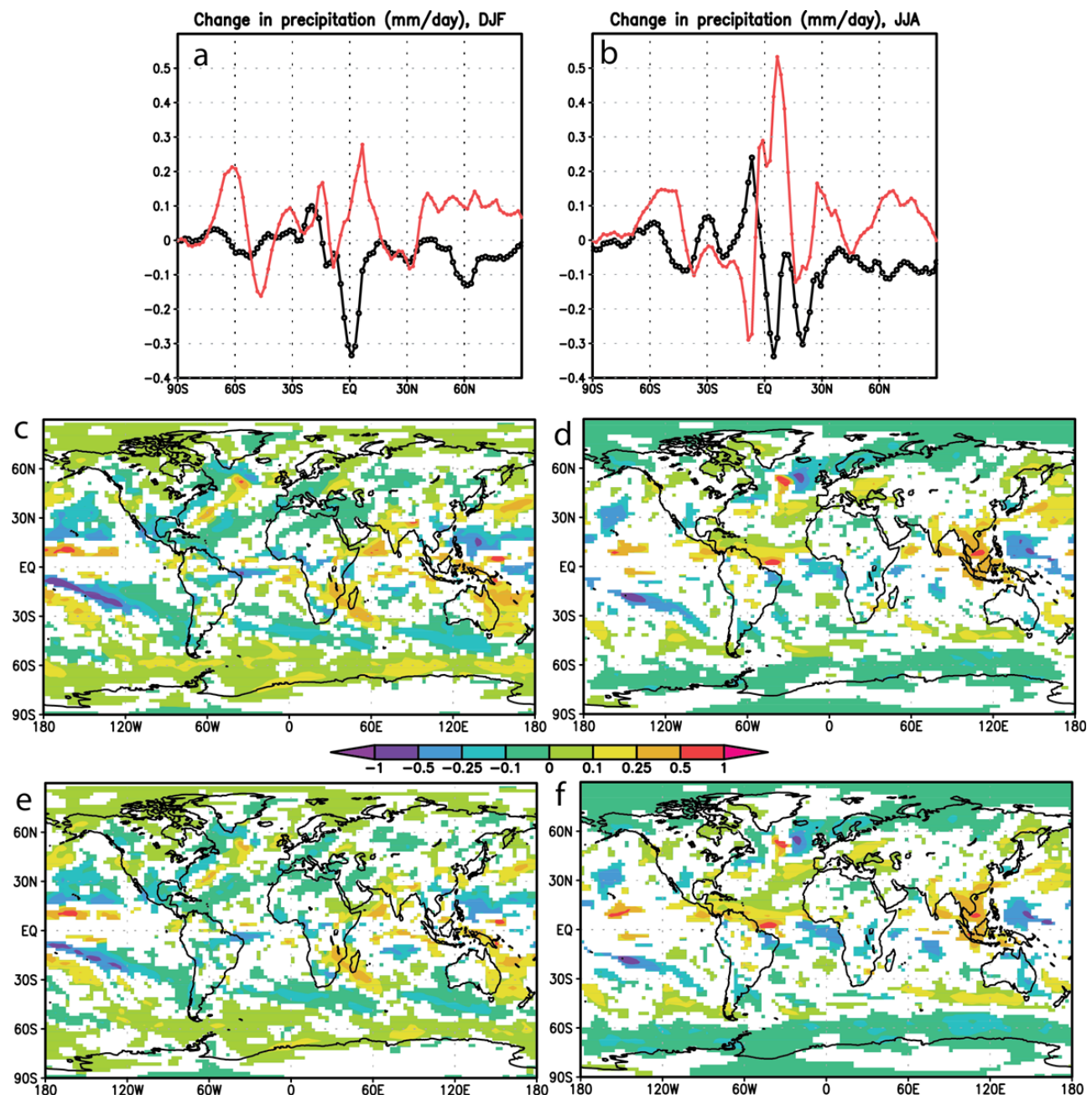

Fig. 5. Model simulated change in average daily precipitation during 1976-2005 relative to piControl for the historical forcing experiments "GHG only" and "aerosol only". Upper panels: zonally averaged changes in daily precipitation amounts for December-January-February (a) and June-July-August (b). Red: GHG only; black: aerosol only. Lower panels: the sum of the annual changes in the GHG only and the aerosol only experiments (c); the difference between the sum in (c) and the total changes in the Historic1 experiment (d); the sum of the annual changes in the GHG only, the aerosol only, and the natural only experiments (e); the difference between the sum in (e) and the total changes in the Historic1 experiment (f). White patches indicate areas where changes are not significant at the $95 \%$ confidence level (two-sided, Student t-test with respect to variance of annual values in piControl). Units are $\mathrm{mm} \mathrm{day}^{-1}$ in all panels.

take into account that not all the CMIP5-models include the negative forcing contributions from both the direct and the indirect aerosol effect which NorESM1-M does. Furthermore, NorESM's gross cloud radiative feedback is negative, and the model's strong AMOC may transfer heat into the deep oceans more efficiently than many other models. Figure 7 also shows that both the inter-model spread and the size of the warming are considerably larger over land than globally, a feature which is also seen when comparing the changes in SST to those of global temperatures in Table 5. The simulated SST changes account for 55-60\% of the changes in global surface air temperatures. This is well known, e.g., from IPCC reports (Trenberth et al., 2007). It can be attributed as a manifestation of the cold-ocean warm-land (COWL) pattern
(Wallace et al., 1996), caused by the low heat capacity of the continents compared to the oceans where heat is mixed in deep water masses.

The geographical distribution of the simulated annual temperature changes for 2071-2100 relative to 1976-2005 for RCP2.6 and RCP8.5 are given in Fig. 8a and b. The temperature increase is considerably larger in RCP8.5 than for RCP2.6. The patterns of COWL and the Arctic amplification are seen for both scenarios. The Arctic sea-ice extent is also projected to decrease by 2100 for all scenarios (see Fig. 9c). The reduction is particularly large for the annual minimum sea-ice extent in the Arctic. The Arctic sea-ice in September has almost disappeared by ca. 2100 for the RCP8.5 scenario. For the other scenario projections, some sea-ice always 
Table 5. Simulated changes in selected global annual data with NorESM1-M from the period 1976-2005 (Historic1) to 2071-2100 based on the four projected representative concentration pathways (RCP) scenarios. The hydro-climatic quantities marked with a star $(*)$ are estimated using the fact that $E_{\mathrm{GLOBAL}}=P_{\mathrm{GLOBAL}}$ in the model. The rightmost columns contain total values simulated for 1976-2005 (Historic1), and the difference between this and piControl.

\begin{tabular}{lllllll}
\hline & RCP8.5 - & RCP6.0 - & RCP4.5 - & RCP2.6 - & Historic1 & Historic1- \\
& Historic1 & Historic1 & Historic1 & Historic1 & 1976-2005 & piControl \\
\hline$T_{2 \mathrm{~m}} / \mathrm{K}$ & +3.07 & +1.86 & +1.65 & +0.94 & 286.78 & +0.50 \\
$\mathrm{SST} / \mathrm{K}$ & +1.76 & +1.06 & +0.95 & +0.59 & 282.92 & +0.34 \\
AREA & -6.24 & -3.48 & -2.97 & -1.43 & 20.76 & -1.14 \\
$P_{\mathrm{GLOBAL}} / 1000 \mathrm{~km}^{3} \mathrm{yr}^{-1}$ & +27 & +17 & +17 & +12 & 521 & 0 \\
$E_{\mathrm{OCEANS}} / 1000 \mathrm{~km}^{3} \mathrm{yr}^{-1}$ & +25 & +15 & +14 & +10 & 442 & +1 \\
$(E-P)_{\mathrm{OCEANS}} / 1000 \mathrm{~km}^{3} \mathrm{yr}^{-1}$ & +8 & +4 & +2 & +1 & 43 & +1 \\
$P_{\text {OCEANS }}^{*} / 1000 \mathrm{~km}^{3} \mathrm{yr}^{-1}$ & +17 & +11 & +12 & +9 & 399 & 0 \\
$P_{\mathrm{LAND}}^{*} / 1000 \mathrm{~km}^{3} \mathrm{yr}^{-1}$ & +10 & +6 & +5 & +3 & 122 & 0 \\
$E_{\mathrm{LAND}}^{*} / 1000 \mathrm{~km}^{3} \mathrm{yr}^{-1}$ & +2 & +2 & +3 & +2 & 79 & -1 \\
\hline
\end{tabular}

Table 6. Simulated changes in annual total precipitation $\left(P, \mathrm{~mm} \mathrm{yr}^{-1}\right)$ and annual total runoff $\left(R, \mathrm{~mm} \mathrm{yr}^{-1}\right)$ with NorESM1-M in Europe, Northern Europe, and the Mediterranean region, from the period 1976-2005 (Historic1) to 2071-2100 based on the four projected representative concentration pathways (RCP) scenarios. The rightmost columns contain total values simulated for 1976-2005 (Historic1), and the difference between this and piControl.

\begin{tabular}{llllllll}
\hline & & RCP8.5 & RCP6.0 - & RCP4.5 - & RCP2.6 - & Historic1 & Historic1 - \\
Historic1 & Historic1 & Historic1 & Historic1 & 1976-2005 & piControl \\
\hline Europe & $P_{\mathrm{EUR}} / \mathrm{mm} \mathrm{yr}^{-1}$ & +32.3 & +12.0 & +25.5 & +42.1 & 862.1 & -19.8 \\
& $R_{\mathrm{EUR}} / \mathrm{mm} \mathrm{yr}^{-1}$ & -11.8 & -16.5 & -10.1 & +5.7 & 316.4 & -2.0 \\
\hline North & $P_{\mathrm{N}-\mathrm{EUR}} / \mathrm{mm} \mathrm{yr}^{-1}$ & +81.9 & +61.2 & +53.5 & +18.9 & 723.1 & +43.3 \\
Europe & $R_{\mathrm{N}-\mathrm{EUR}} / \mathrm{mm} \mathrm{yr}^{-1}$ & +24.1 & +21.8 & +11.6 & -10.3 & 468.4 & +40.6 \\
\hline $\begin{array}{l}\text { Mediterranean } \\
\text { region }\end{array}$ & $P_{\mathrm{MED}} / \mathrm{mm} \mathrm{yr}^{-1}$ & -79.7 & -36.3 & -5.8 & +20.6 & 611.5 & -41.1 \\
\hline
\end{tabular}

remains. The response in the Southern Hemisphere is considerably smaller. The simulated response from 1976-2005 to 2071-2100 in the total global and annual mean sea-ice area is given for each RCP scenario in the bottom row in Table 5 . In relative numbers the reduction varies from ca. $7 \%$ (RCP2.6) to ca. $30 \%$ (RCP8.5).

\subsection{Precipitation}

The climatology of precipitation and dry spells has strong impacts on the natural environment as well as human society. Changes in annual total amounts as well as the intensity of precipitation events are important in this connection. As discussed by Bentsen et al. (2012) NorESM1-M overestimates the global precipitation by the end of the 20th century by ca. $0.14 \mathrm{~mm} \mathrm{~d}^{-1}\left[(2.81-2.67) \mathrm{mm} \mathrm{d}^{-1}\right]$ compared to the GPCP data (Adler et al., 2003), where the overestimations are particularly pronounced in the tropics. However, Trenberth (2011) mentions that GPCP values may underestimate warm rain in the extra-tropics and refers to increased

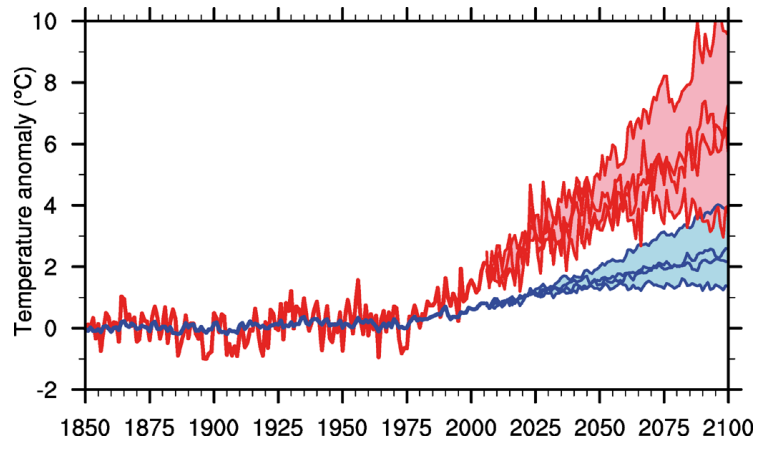

Fig. 6. Model simulated development from 1850 to 2100 in surface air temperature relative to the 1850-1899 average for Historic1 until 2005 followed by a range defined by the four RCP scenario projections. Blue: global data, red: the $\mathrm{NH}$ polar area north of $65^{\circ} \mathrm{N}$. The diagram can be compared with Fig. 25 in Bentsen et al. (2012). 
estimates of $5 \%$ over the ocean. NorESM1-M also has a slightly too intense hydrological cycle, since oceanic evaporation is about $4 \%$ larger than estimates from synthesized observational data (Trenberth et al., 2011). Opposed to many other global climate models with too fast recycling of water vapour, NorESM1-M slightly overestimates the atmospheric residence time of oceanic water vapour, and the atmospheric transfer of water vapour from ocean to land is overestimated by about $8 \%$ compared to the estimate of Trenberth et al. (2011).

Figure 8 shows projections of relative change (\%) in annual precipitation amounts by 2071-2100 relative to 19762005 for the extreme scenarios RCP2.6 and RCP8.5. In general the patterns are the same, but RCP8.5 has larger anomalies. Some increases occur over arid regions giving very large relative changes, for example, over central parts of northern Africa. Otherwise, there are strong increases over the tropical Pacific Ocean paired with strong decreases in the subtropics. There is also reduced precipitation in the Mediterranean region and in southern parts of North America. Otherwise there are mainly precipitation increases, including the polar latitudes in both hemispheres. Many of these features are more pronounced in the seasonal maps for RCP8.5. Drying in the northern hemispheric continents is more pronounced in $\mathrm{NH}$ summer, whilst in the $\mathrm{NH}$ winter the precipitation increase is more ubiquitous.

Figure 9a and $\mathrm{b}$ show the simulated time development of the difference between evaporation and precipitation $(E-P)$ and evaporation $(E)$ integrated over the global oceans. The oceanic $E-P$ is the net water vapour transported from ocean to land in the atmosphere, while the oceanic $E$ is a measure of the intensity of the hydrological cycle. Both quantities increase in the simulations of the RCP scenarios. The budget changes in Table 5 indicate that all gross quantities, except for one, increase with the size of the forcing by 20712100 compared to $1976-2005$. The global annual precipitation amounts increase by $2.3-5.2 \%$, the oceanic evaporation by $2.3-4.5 \%$, the net atmospheric transfer from ocean to land by $2-18 \%$, and the precipitation on land by $2.5-8.2 \%$, where the low numbers are for RCP2.6 and the high for RCP8.5.

The quantity that does not increase is evaporation from land which, thus, in practice is preserved while both the net flux of vapour from ocean to land and the precipitation over land increase. Evaporation from the land surface is strongly influenced by direct water availability in the upper soil and by plant transpiration which provides access to water in deeper soil layers. Both these would normally be expected to increase with increased precipitation. Since the model does not predict this to happen for the total land evaporation, the soil is being allowed to dry out more by either having longer dry spells between precipitation events or by increasing the spatial scale of dry sub-regions. In both cases, the average intensity of precipitation over land must increase, since the predicted precipitation increase will take place over smaller fractions of space or time. Thus, we can hypothesize that in

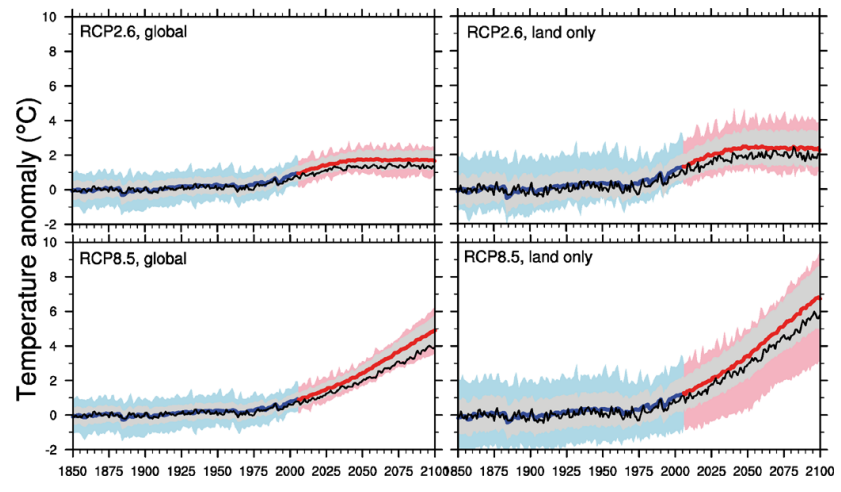

Fig. 7. Model calculated annual surface air temperature anomalies relative to the 1850-1899 average for RCP2.6 (upper panels) and RCP8.5 (lower panels), averaged globally (left panels) and over land areas (right panels). Black lines: NorESM1-M; blue and red lines: ensemble mean over 15 other models contributing to CMIP5, grey shading: one standard deviation on each side of the ensemble mean; blue and red shading: range defined by max and min values amongst the 15 models.

NorESM1-M future climate change scenarios there is an increase in both the precipitation intensity and space-time fraction of dry spells. Such effects were deduced for a warmer climate by Trenberth et al. (2003) and further elaborated by Trenberth (2011). The relevance of dry spells in diagnosing the intensity of the hydrological cycle was thoroughly discussed and analysed by Giorgi et al. (2011).

Table 6 analyses the possible future situation in Europe for the RCP scenarios. The table clearly shows that the NorESM1-M simulations produce a striking difference between increased precipitation in Northern Europe and more dry conditions in Southern Europe towards 2100. According to the simulations in Historic1, such a development may already have occurred.

\subsection{AMOC and ocean temperatures}

We have already discussed the possible regulating role of the AMOC for the impacts of radiative forcing on near surface air temperature, SST, surface evaporation and melting of seaice. This 3-D current is regarded as a part of the global ocean conveyer belt. A common view is that the upward closing branch is a large scale balance between upwelling and diapycnal mixing (e.g., Munk and Wunsch, 1998). AMOC is driven by wind stress and by thermohaline forcing. The latter occurs when cold and saline water is produced at high latitudes and becomes negatively buoyant and sinks.

Under anthropogenic climate change, increased precipitation and melting of the cryosphere may stabilise the vertical water column at high latitudes and lead to a reduced AMOC (e.g., Hofmann and Rahmstorf, 2009). We have already seen that NorESM1-M simulates increased precipitation in the northern North Atlantic Ocean and reduced precipitation in 

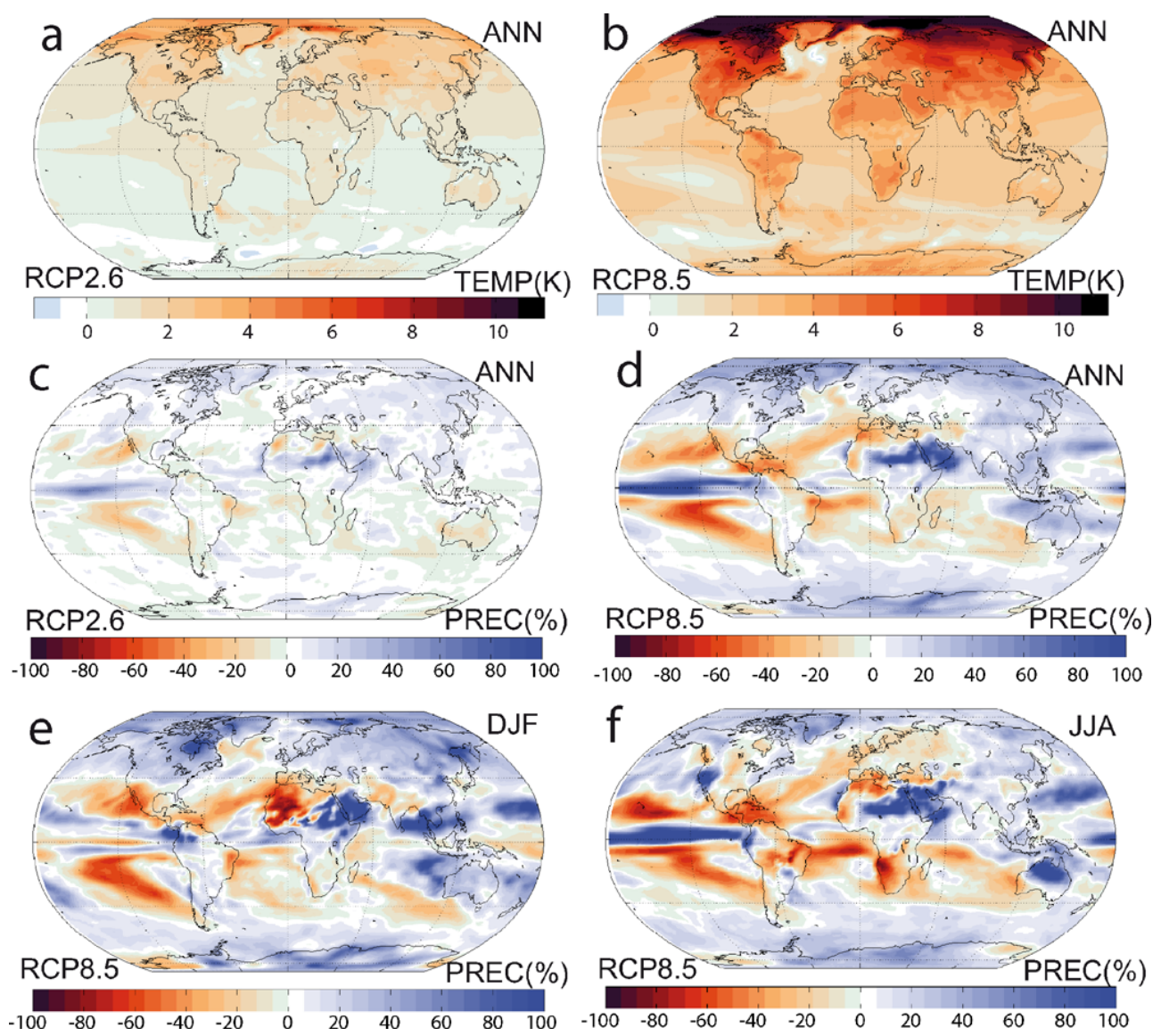

Fig. 8. Model simulated change in mean surface air temperature $(K)(\mathbf{a}, \mathbf{b})$ and percentage change in precipitation (c, d, e, f) from 1976-2005 to 2071-2100. Annual averages for RCP2.6 (a and c) and for RCP8.5 (b and d); RCP8.5 precipitation for (e) Dec-Jan-Feb and (f) Jun-JulAug.

the subtropics under RCP scenarios (Fig. 8). Observational studies indicate that surface water has become fresher in areas relevant for deep water formation already during the recent decades (Curry and Mauritzen, 2005). A slower AMOC may be associated with reduced poleward transport of heat in the upper ocean and cause colder climate regionally over the northern North Atlantic Ocean, the Arctic, and in Northwest Europe. Persistent wind stress in the storm-track regions combined with increased subtropical surface salinity may compensate if more saline water is transported northwards by the surface wind driven currents (Bethke et al., 2006).

Figure 10 (upper panel) shows the time series of maximum AMOC strength at $26.5^{\circ} \mathrm{N}$ in the NorESM1-M runs piControl, Historic 1, 2 and 3, and the 4 RCP scenarios. The piControl time series has a mean value of $30.8 \mathrm{~Sv}$ and a small but significant (p-value $<0.01$ ) linear trend of $-0.6 \mathrm{~Sv}$ over $500 \mathrm{yr}$ (Bentsen et al., 2012). The historical experiments do not deviate significantly from the long-term evolution of the piControl experiment, which shows considerable amplitudes due to unforced internal variability. However, they all show a decreasing AMOC strength after about 1980. In the moving averaged time series, two of the historical members end at an AMOC strength near the minimum value encountered during the whole piControl integration.

The reduction seen in the RCP experiments is considerably larger than the trend and variability of the piControl. When comparing the mean AMOC strength of the years 2091-2100 in the scenario experiments to the mean strength of the control, the reductions are 3.6 Sv for RCP2.6, 5.1 Sv for RCP4.5, 5.6 Sv for RCP6.0, and 9.9 Sv for RCP8.5. The relative reductions are, thus, approximately $12 \%, 17 \%, 18 \%$, and $32 \%$, respectively. In the SRES A1B scenario experiment of 16 models participating in CMIP3, Schneider et al. (2007) found a mean reduction of maximum AMOC strength at $30^{\circ} \mathrm{N}$ of about $4 \mathrm{~Sv}$ from year 2000 to 2100 . This amounts to an average decline of about $25 \%$. The SRES A1B scenario is closest to the RCP6.0 scenario in terms of estimated radiative forcing towards year 2100 (Houghton et al., 2001; van Vuuren et al., 2011). The NorESM1-M simulation based on the RCP4.5 scenario, which was extended to year 2300 with constant aerosol emissions and greenhouse gas concentrations 
after year 2100, shows a rather stable AMOC strength of 25$26 \mathrm{~Sv}$ after year 2100 .

The zonal mean temperature change for years 2071-2100 of NorESM1-M RCP8.5 compared to corresponding years of the piControl experiment is shown in the two bottom panels in Fig. 10. In the upper $200 \mathrm{~m}$, the warming is in excess of $2 \mathrm{~K}$ most places except where sea-ice is present and constrains the temperature at the freezing temperature. The warming is in general reduced with depth, and below $3000 \mathrm{~m}$ the warming signal is weak, particularly in the global average shown in the right panel of Fig. 10. At high latitudes, the warming penetrates deeper. A generally stronger warming signal is seen for the Atlantic Ocean in the left panel of Fig. 10 compared to the global ocean. Also, for the Atlantic Ocean, the upper ocean temperature increase is efficiently communicated to the ocean interior at high latitudes.

The overturning circulation of the Atlantic seems to carry a warming signal southward in the Atlantic at 2000-3000 m depth. Given that AMOC strength is reduced by a third by 2100 , further penetration of heat to the deep ocean will be considerably reduced, although it will remain strong in this model. A larger fraction of the greenhouse gas heating in the RCP8.5 scenario will nevertheless remain in the atmosphere and contribute to enhance the globally averaged surface warming. However, a considerably reduced heating (possibly cooling) may occur regionally at high latitudes adjacent to where the negatively buoyant water normally is formed in the Atlantic Ocean. In order to study such consequences, the RCP8.5-based simulation should be prolonged. Some caution should also be taken with regard to these results since NorESM1-M probably overestimate the strength of AMOC in the first place.

\section{Changes in regional flow patterns}

The climate of the mid-latitudes is closely linked to largescale cyclones that develop and propagate in the westerly jet-stream systems. In particular, extreme precipitation and flooding are linked to storminess and transport in the associated warm conveyor belt (Stohl et al., 2008; Gimeno et al., 2011). Extra-tropical cyclones are also important vehicles for the atmospheric meridional transport of heat, humidity and momentum between the low and high latitudes, as well as the maintenance of the jet-streams themselves (e.g., Bratseth, 2001, 2003). Absence of cyclones associated with persistent blocking events is likewise important for the occurrence of droughts. Furthermore, the changed occurrence of flow regimes or prevalent intrinsic weather modes can be claimed to be a regional manifestation of global climate change (Corti et al., 1999; Branstator and Selten, 2009). In this section, we address these aspects of the NorESM1-M simulation results, emphasising the Northern Hemisphere (NH) and ENSO.
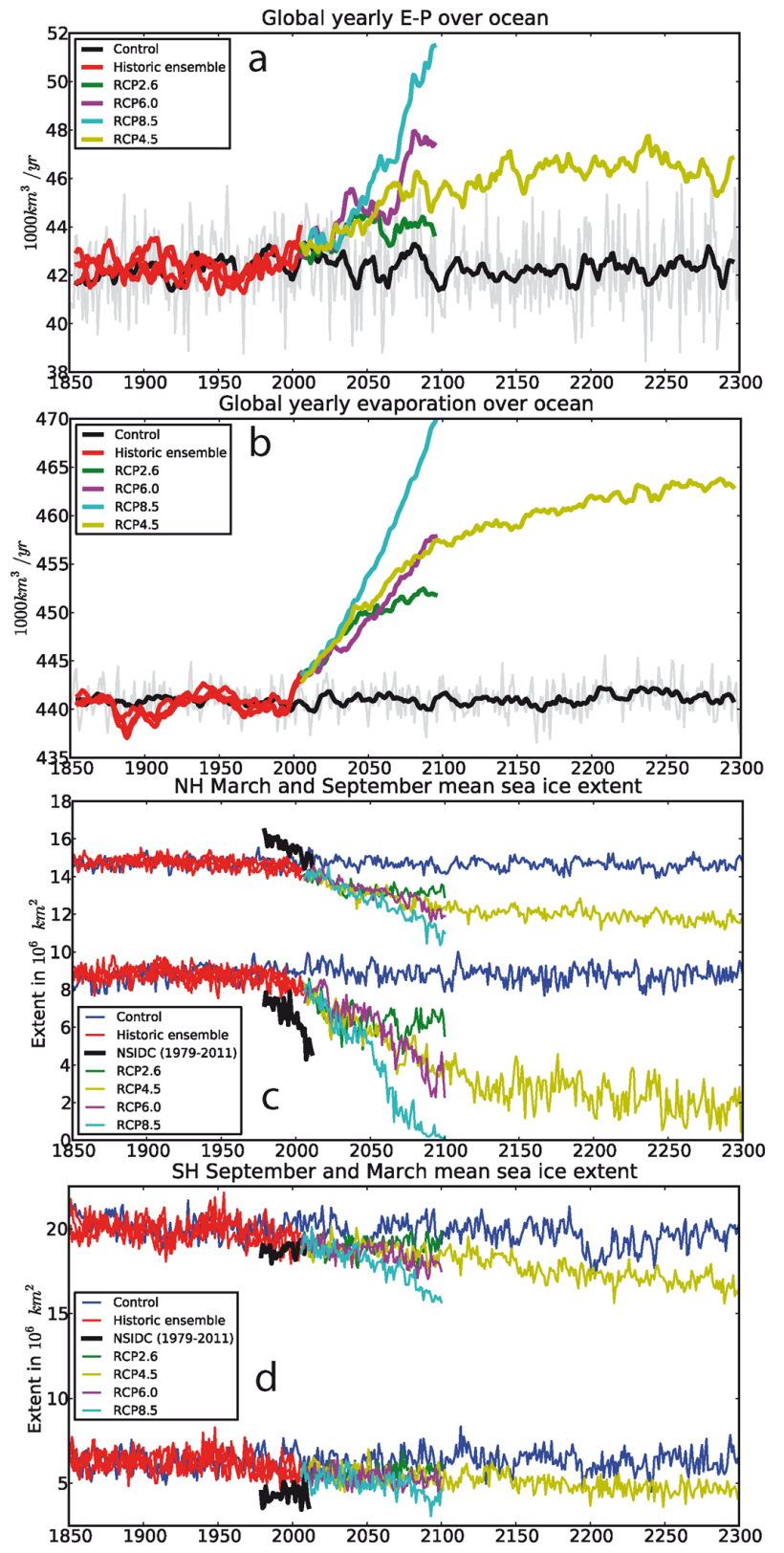

Fig. 9. Decadal moving average annual evaporation minus precipitation (a) and evaporation (b) from the oceans, and the northern (c) and southern hemispheric (d) March and September sea-ice extent during the NorESM1-M simulations for 1850 to 2300. Black in (a) and (b) and blue in (c) and (d): the piControl, red: 1850-2005 Historic1, 2, and 3; dark green: RCP2.6 2005-2100; light green: RCP4.5 2005-2300; magenta: RCP 6.0 2005-2100; cyan: RCP8.5 2005-2100. Black curves in (c) and (d) are sea-ice extents estimated from observations (NSIDC, Fetterer et al., 2009).

\subsection{NH storminess}

The climatological storminess in the Northern Hemisphere (NH) extra-tropics simulated with NorESM1-M is diagnosed using the standard deviation of 2.5-6 days band-pass filtered 

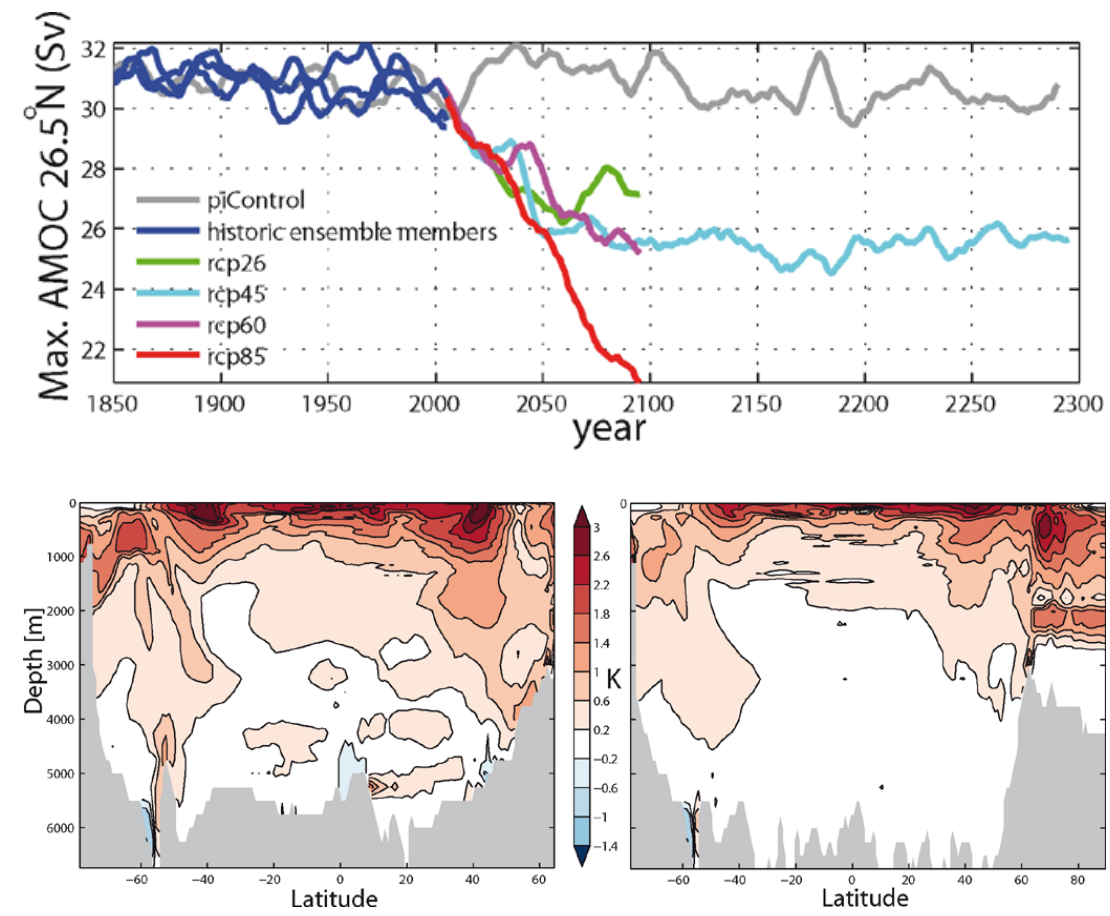

Fig. 10. The top panel shows decadal moving averages of the annual max AMOC at $26.5^{\circ} \mathrm{N}$, where grey is piControl, blue are Historic1, 2, and 3, green is RCP2.6, turquoise RCP4.5, violet RCP6.0, and red is RCP8.5. The bottom two panels show annual and zonal mean NorESM1-M simulated ocean temperature change for years 2071-2100 with RCP8.5 compared to piControl. Left: the Atlantic Ocean, right: global oceans.
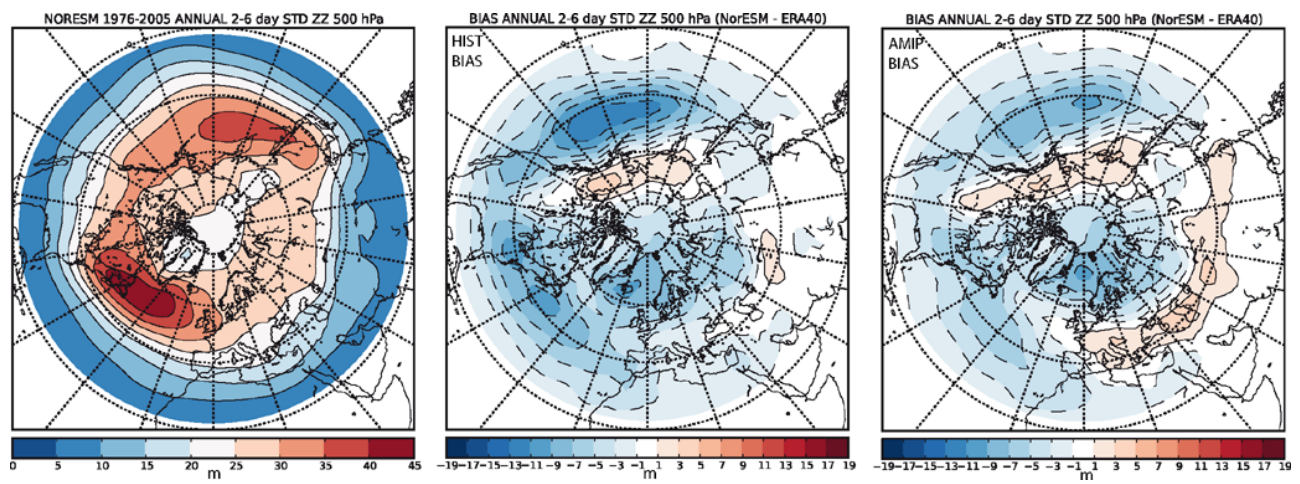

Fig. 11. Diagnosis of NH extra-tropical storminess in NorESM1-M simulations of 1976-2005 (Historic1) by applying a band-pass frequency filter, emphasising periods from 2.5 to 6 days, to the $500 \mathrm{hPa}$ geopotential height (left). The middle panel shows bias error when compared to the ERA40 reanalysis data for 1976-2002 (Uppala et al., 2005), and the right panel shows the corresponding bias for the period 1979-2005 of the AMIP simulations with NorESM1-M run without coupling to the ocean model, but with SST-fields prescribed from observations.

$500 \mathrm{hPa}$ geopotential height. The band-pass filter is the same as used by Blackmon (1976), which has been shown to retain baroclinic waves consistent with theoretical and modelling studies (e.g., Chang et al., 2002 and references therein). Although this field represents baroclinic wave activity we will refer to it here as a measure of storm track activity. Figure 11 shows the annual mean storm tracks for the NorESM1-M historical simulation compared to the ERA-40 reanalysis (Uppala et al., 2005). Many of the main characteristics of the NH storm tracks are well simulated, although the amplitude of the band-pass filtered variability overall are slightly too weak. Note that this amplitude bias is significantly reduced for the AMIP run of the NorESM1-M model with prescribed SSTs based on observations. Parts of the bias in the fully coupled NorESM1-M can, thus, be attributed to systematic errors in the simulated SST field. Another notable bias is found over the North-Atlantic Ocean where the storm track is too zonal and lacks the characteristic poleward tilt in the 
ERA-40 data. This bias is very similar to that reported for the CAM3 model (Hurrell et al., 2006), and the bias appears to be intrinsic to the atmospheric model component, since it is virtually unchanged in the AMIP run of the NorESM1-M.

Figure 12 shows the projected changes for 2071-2100 compared to 1976-2005 for the RCP8.5 scenario. The annual mean change is dominated by a slight general weakening of the band-pass filtered variability except over the northern North-Atlantic Ocean where a poleward shift in the storminess is apparent. This poleward shift is prominent mainly during summer and autumn. Although the shift is statistically significant at the $5 \%$ level relative to the variational spread in the time series, Fig. 12 also includes the spread between the 3 historical NorESM1-M simulations for the period 1976-2005. This sample is of course too small to adequately represent the model's internal variability as an ensemble, but the amplitude of the poleward shift as well as the more general weakening can, at least, be seen to exceed this ensemble spread. A poleward shift of mid-latitude storm tracks has also been diagnosed in many other climate model simulations as a response to anthropogenic greenhouse-gas forcing (e.g., Yin, 2005).

\subsection{NH blocking}

Whilst storminess is associated with frequent occurrence of precipitation and possibly flooding, the blocking phenomenon is closely connected with persistent anticyclones, which tend to suppress precipitation at mid-latitudes for periods of up to several weeks. Incidents of extensive droughts can be associated with blocking, and the ability of climate models to simulate and project the climatic occurrence of droughts at mid-latitudes will be influenced by their ability to simulate blocking. Many blockings will also include a cold cyclone with low static stability and heavy convective storms.

To diagnose atmospheric blocking, we use the index originally proposed by Lejanäs and Økland (1983) and later modified by Tibaldi and Molteni (1990) (TM). The TM index uses a persistent reversal of the gradient of the $500 \mathrm{hPa}$ geopotential height around a central latitude $\left(50^{\circ} \mathrm{N}\right)$ as an indicator of blocked flow. The central latitude is allowed to vary by approximately $3.8^{\circ}$ ( 2 grid points in the NorESM) to include small latitudinal shifts in the block. The blocks were further required to last for at least 5 days and be present at $7.5^{\circ}$ consecutive longitudes.

Pelly and Hoskins (2003) have shown that a fixed central blocking latitude suitable for detecting blocks over the North Atlantic leads to spurious detection over the North Pacific. We, therefore, also calculate a "vTM" index where the central latitude varies with the longitude of the climatological storm track. The central latitude is defined as the maximum of the standard deviation of the 2.5-6 days band-pass filtered geopotential height anomalies at $500 \mathrm{hPa}$. To account for the seasonal cycle of the storminess, the central latitude for a
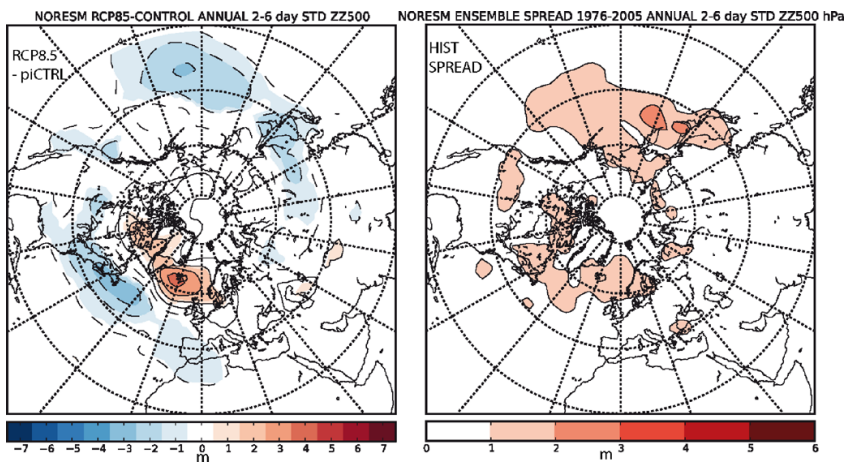

Fig. 12. NorESM1-M simulated change from 1976-2002 to 20712100 in NH extra-tropical storminess, diagnosed as described in Fig. 11, using the RCP8.5 projection scenario (left). Colours indicate significant changes on the $95 \%$ confidence level. The right panel shows the standard deviation in the storminess amongst the three ensemble-members Historic1-3 for 1976-2005, revealing that the significant changes diagnosed in the left panel are considerably larger for the main maxima.

given month is calculated as the climatological 3-month average centred on that month.

Figure 13 shows the seasonal blocking frequency for the NorESM1-M Historic1 simulation for 1976-2005 compared to the ERA-40 reanalysis for 1979-2002. The variable latitude "vTM" index is shown. For all seasons the model largely fails to adequately simulate blocking over the North-Atlantic Ocean and western Europe in NH winter and spring. This is consistent with the too zonal propagation of storms in this sector (Fig. 11). This common deficiency amongst climate models (e.g., D'Andrea et al., 1998) may be partly attributed to the coarse resolution, as the investigation of Jung et al. (2012) suggests that around $40 \mathrm{~km}$ resolution is needed. Matsueda et al. (2009) even found that a horizontal resolution of $20 \mathrm{~km}$ was required to accurately simulate the frequency of Euro-Atlantic blocking, and that higher resolution generally improves the representation in this sector. Further to the east, over the Eurasian continent, blocking is better simulated but exaggerated. Similar results are seen when blocking is defined at $50^{\circ} \mathrm{N}$ fixed latitude, although the bias is smaller in spring (not shown). For blocking in the NH summer and fall, the Euro-Atlantic blocking is better reproduced, but still underestimated.

Over the Pacific Ocean the simulated blocking frequency is closer to the observed, which is consistent with the conclusion by Matsueda et al. (2009) that the required horizontal resolution is coarser in the Pacific sector than in the Atlantic. It should be noted that there is some evidence that blocking deficits also can be reduced, even with relatively coarse resolution, by improving the SST field and reducing the time mean bias in the westerlies (Scaife et al., 2011).

The projected changes in blocking frequency during 2071-2100 for the RCP8.5 scenario compared to 1976-2005 
Seasonal blocking frequency (vTM index)
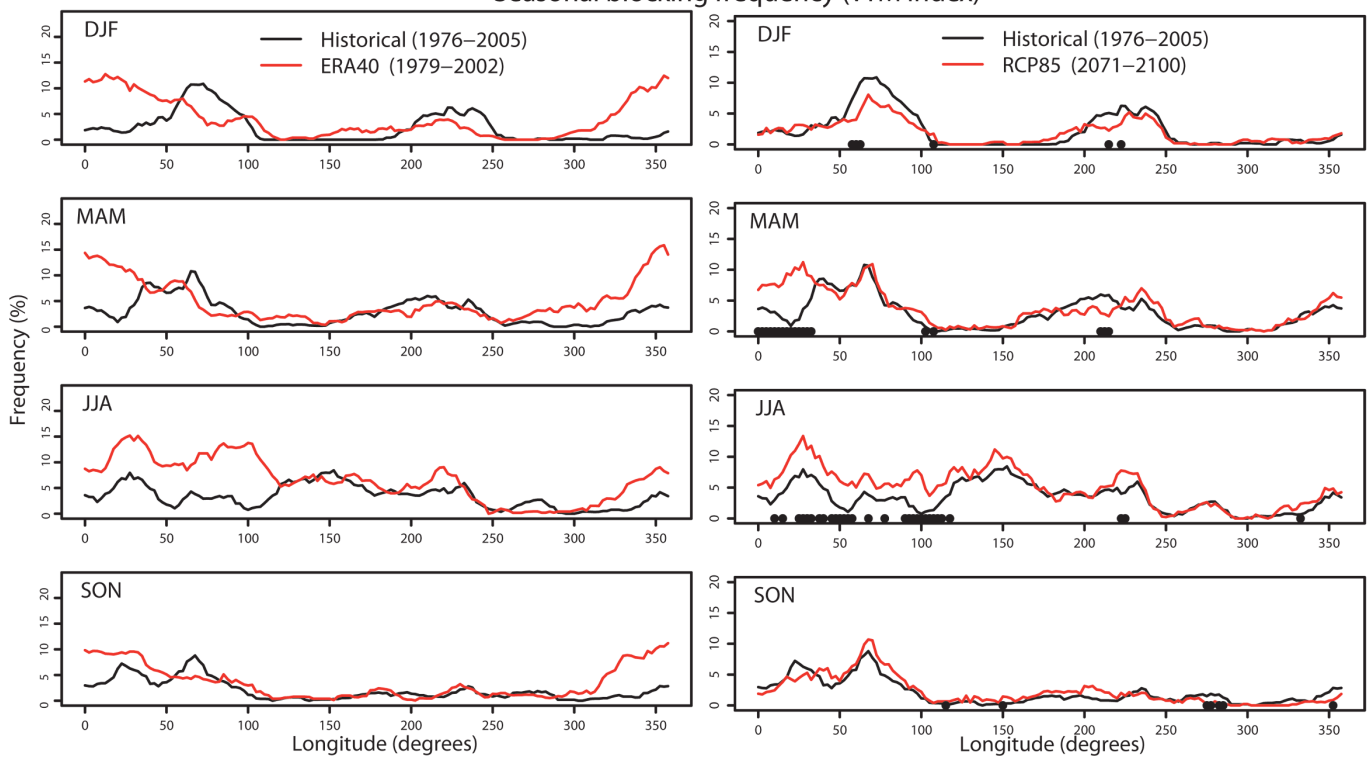

Fig. 13. Northern hemispheric seasonal blocking statistics for the Tibaldi and Molteni (1990) (vTM) index diagnosed relative to the latitudes of the seasonally averaged position of the westerlies (Pelly and Hoskins, 2002). Left panels are for the simulated NorESM1-M Historic1 for 1976-2005 compared to ERA40 statistics for 1976-2002, and right panels are projections for 2071-2100 with the RCP8.5 scenario compared to the period 1976-2005 (Historic1) with NorESM1-M. Dots signify longitudes where differences are significant at the 95\% confidence level.

are shown in Fig. 13. Using again the "vTM" index an increased blocking frequency is apparent for the sector 0 $100^{\circ} \mathrm{E}$ for the summer months as well as in the sector 0 $40^{\circ} \mathrm{E}$ during spring. We emphasise, however, that since there are large systematic biases in blocking frequency for the same sectors, these projections must be interpreted with great caution. The projected changes diagnosed using the index with fixed $50^{\circ} \mathrm{N}$ latitude (not shown), show considerably smaller changes than "vTM", which may be due to the simultaneous pole-ward shift in the position of the westerly air currents. This contradicts the use of fixed latitudes for the blocking index. Such sensitivity to choice of index has also been reported by Barnes et al. (2012), and adds to the uncertainties connected with blocking simulation in climate models. The projected increase in blocking frequency can be linked to the reduced precipitation in the region except for Northern Europe.

\subsection{NH EOF-analysis}

In order to describe the low frequency variability in the NorESM1-M, an EOF (empirical orthogonal function) analysis has been applied to monthly mean $500 \mathrm{hPa}$ geopotential height anomalies during extended winter seasons (DJFM) from 1976 to 2005, where the DJFM-months define the year associated with each season. The three historical ensemble members for the mentioned period define the climatology about which the anomalies are calculated.
To calculate the EOFs (see e.g., Bjørnsson and Venegas, 1997; Hannachi et al., 2007; Monahan et al., 2009) the anomalies for each historical ensemble member are detrended by calculating deviations from a $5 \mathrm{yr}$ moving average, and a common seasonal cycle for the simulated 19762005 period estimated by subtracting separate averages for each month $(3 \times 30$ values are averaged per month). The EOFs, thus, represent spatial structures of the $500 \mathrm{hPa}$ geopotential height fields associated with non-seasonal variations up to a few years, similar to the analysis of Corti et al. (1999) which was further extended by Molteni et al. (2006), based on NCEP re-analysis data (Kalnay et al., 1996).

The detrended, non-seasonal monthly anomalies are formally organised into a matrix $\mathbf{A}$, where the rows are the $3 \times 30 \times 4$ spatial anomaly patterns and the columns are the monthly values of the anomaly in each point in space. The EOFs are the eigenvectors (w.r.t. the standard Euclidian inner product) of the covariance matrix, $\mathbf{C}=\mathbf{A}^{T} \mathbf{A}$, i.e., $\mathbf{C R}=\boldsymbol{R}^{T} \Lambda$, where $\Lambda$ is the diagonal matrix containing the eigenvalues, $\lambda_{i}$ of $\mathbf{C}$. The column vectors in $\boldsymbol{R}$ are the mutually orthogonal eigenvectors $\boldsymbol{e} \boldsymbol{o} \boldsymbol{f}_{i}$ of $\mathbf{C}$. Each eigenvalue measures the fraction of the total variance that the corresponding EOF pattern accounts for.

The associated principal components (PC) are time-series of the projections of $\mathbf{A}$ onto the EOFs: $\boldsymbol{P} \boldsymbol{C}_{i}=\mathbf{A}^{T} \cdot \boldsymbol{e o f} \boldsymbol{f}_{i}$. In addition to calculating the PCs for the three historical simulations for the DJFM-winters 1976-2005, the time-series of the projections of the non-detrended anomaly data on each EOF have been estimated for the GHG only (GHG), aerosol 
only (AER), and natural forcing only (NAT), as well as the projected scenario RCP8.5. Note that all anomalies are calculated w.r.t. the 1976-2005 climatology for the three historical ensemble members before projection onto the EOFs.

One reason for using EOF-based flow regime analysis in the context of climate change, is that internal dynamics in the climate system may determine the patterns of climate response to external forcing rather than the structure of the forcing itself (Palmer, 1999; Branstator and Selten, 2009; Iversen et al., 2009), although this view needs to be extended to account for local internal feedbacks in the climate system, which can be particularly strong in connection with Arctic snow and sea-ice (Boer and Yu, 2003).

The obtained projections onto selected EOFs for scenario simulations can, therefore, be directly compared with the PCs of the three historical ensemble members. If systematic differences are found, these can potentially be attributed to the differences in external conditions, whilst differences between the historical ensemble members' PCs will reflect internal variability. At present, we have not estimated any probability density functions for projection coefficients; a method whose validity is under some discussion (Stephenson et al., 2004; Molteni et al., 2006).

The validity of potential results described above will not be convincing if the EOFs for the modelled fields differ considerably from "observed" EOFs from re-analysis data (e.g., Corti et al., 2003). One additional purpose of an analysis like this is, therefore, to investigate to what extent selected atmospheric flow regime patterns are reproduced in NorESM1-M. Hence, we have also calculated EOFs to the NCEP reanalysis data for the same extended winter seasons of 1976-2005, in the same way as was done by Corti et al. (1999) and Molteni et al. (2006), but for a shorter period.

Figure 14 shows the $500 \mathrm{hPa}$ geopotential height pattern for the 4 leading EOFs from the de-trended monthly data for the three ensemble members of the historical simulations with NorESM1-M. Each EOF is scaled to represent one standard deviation of its principal component. They are then compared to the two leading EOFs calculated in the same way for the reanalysis data from NCEP for the same 30 winters (Kalnay et al., 1996). The first EOF for both the reanalysis and the model represents the Arctic Oscillation (AO) (Thompson and Wallace, 2000), or alternatively the Northern Annular Mode (NAM). The shapes are slightly different in NorESM1-M with a maximum centred in the central Arctic, while the NCEP data has a centre displaced over to the Atlantic sector, but both have secondary maxima of the opposite sign in southern Europe, north-eastern North America, and the northern Pacific Ocean.

The second EOF of NorESM1-M differs significantly from that of the NCEP data. Both EOFs are combinations of patterns reminiscent of the Pacific North American (PNA) (Wallace and Gutzler, 1981) and North Atlantic Oscillation (NAO) (Barnston and Livezey, 1987). However, while the NCEP EOF2 is dominated by the latter in strong combination
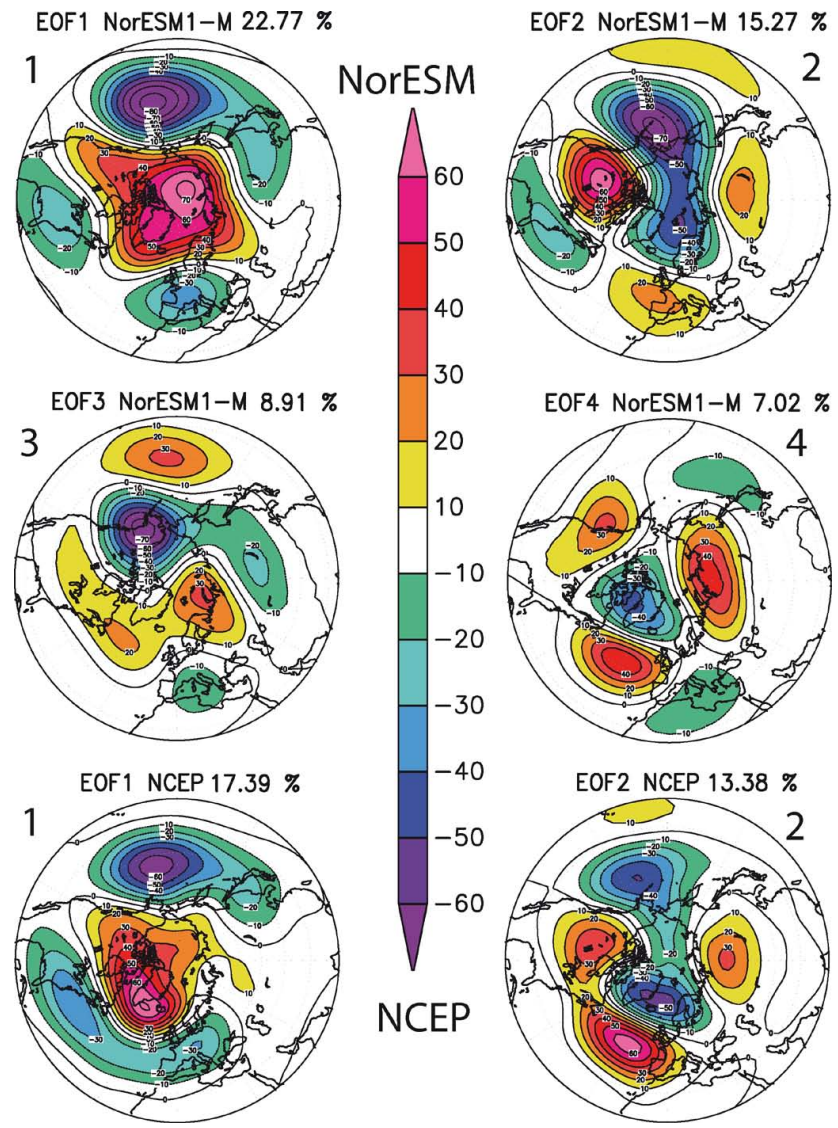

Fig. 14. First and second rows show the 500-hPa-geopotential height associated with the 4 leading EOF-vectors for detrended, monthly average anomalies of the $500 \mathrm{hPa}$ geopotential height for December-March over the years 1976-2005, based on the three ensemble members (Historic1, 2, and 3) simulated with NorESM1-M. Seasonal variations are removed by calculating anomalies relative to the $30-\mathrm{yr}$ average for each month, while trends are removed by subtracting the 5-yr moving average. The third row shows the corresponding maps of the 2 leading eof-vectors calculated in the same way for the same $30 \mathrm{yr}$ using the NCEP re-analysis data (Kalnay et al., 1996).

with the cold-ocean-warm-land (COWL) (Wallace et al., 1996), the NorESM1-M EOF2 is dominated by the PNA with little resemblance of the COWL pattern. Furthermore, the NAO resemblance in NorESM1-M's EOF2 is weak and displaced towards east over Europe. The COWL pattern only turns up convincingly in EOF4 for NorESM1-M, and in this case combined with a NAO pattern which is considerably more correctly positioned than in EOF2. It appears that a suitable combination ("rotation") of EOF2 and EOF4 from NorESM1-M can be made to better resemble EOF2 from NCEP than any of them do separately. Such a combination was, for example, made by Corti et al. (2003) for results from a simpler climate model. The third EOF of NorESM1-M resembles the EOF4 of NCEP (not shown). 


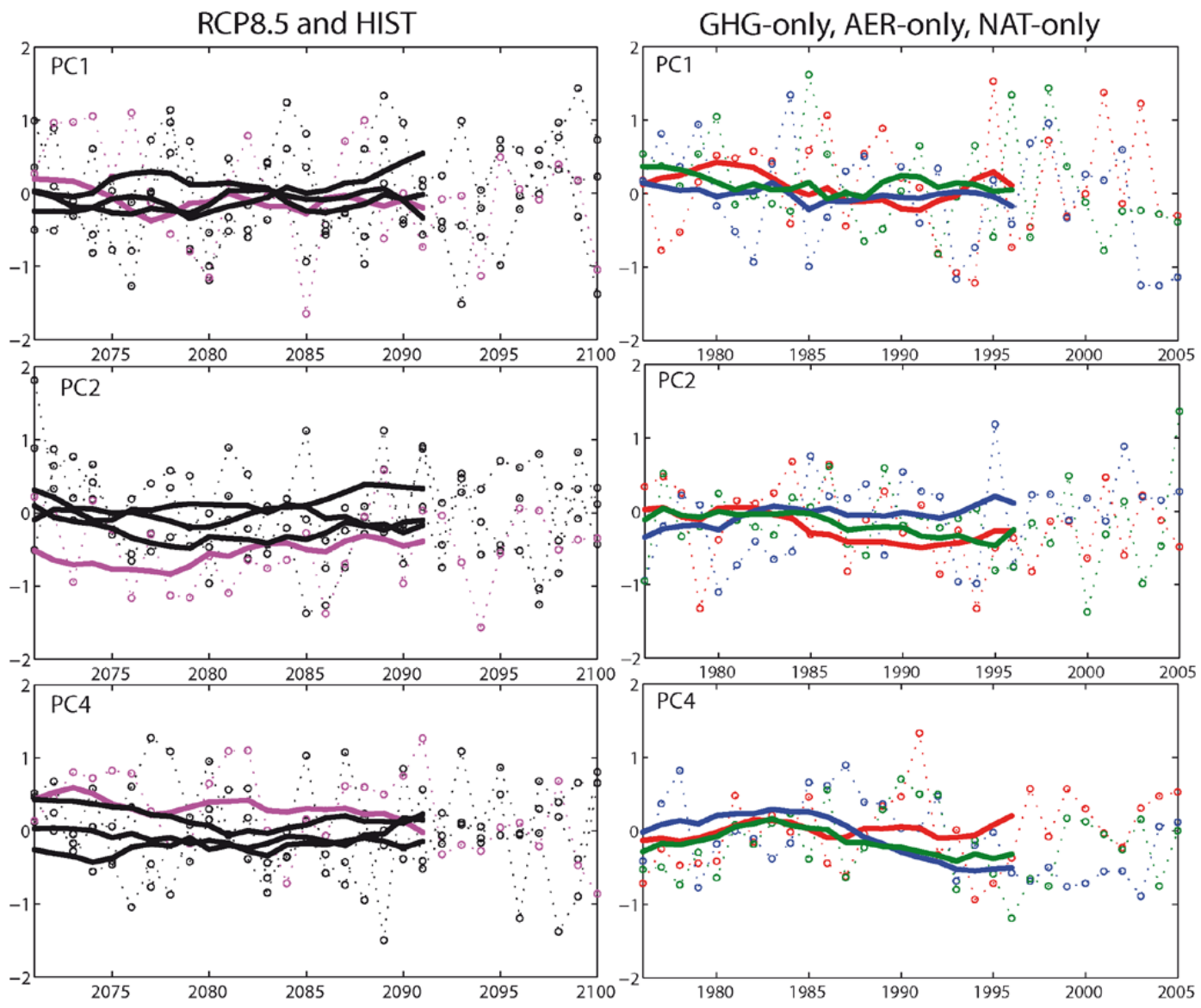

Fig. 15. The left column shows components of the non-detrended geopotential height anomalies for each 4-month season (DJFM) of the 3 historical ensemble members for 1976-2005 (black dashed lines and circles), and for the simulated climate projection for each 4-month season of the years 2071-2100 (denoted on the x-axes) using the RCP8.5 scenario with NorESM1-M (magenta dashed lines and circles). Thick lines are 10-yr forward moving averages. Right column shows similar components for the experiments with GHG-only (red), Aerosolonly (blue), and Natural forcing only (green) for 1976-2005.

Another difference between NorESM1-M and NCEP is revealed by the eigenvalues associated with the EOFs, i.e., the "explained variance" of each EOF as shown by the percentages above each EOF in Fig. 14. The low-order EOFs from the NorESM1-M data "explain" a larger portion than the corresponding low-order NCEP EOFs.

As a separate test we have also calculated EOFs over a sector of the Northern Hemisphere $\left(80^{\circ} \mathrm{W}-40^{\circ} \mathrm{E}\right.$ and $20^{\circ} \mathrm{N}-$ $80^{\circ} \mathrm{N}$ ) for both NorESM1-M and NCEP data (not shown). In this case, the first sectorial EOF explains approximately the same amount of the variance in NorESM1-M (33.9\%) and NCEP $(33.4 \%)$. However, the patterns are very similar to the hemispheric leading EOFs over the sectors. Thus, the NAO-pattern in NorESM1-M's EOF1 is displaced towards the east compared to NCEP. The patterns of the second EOFs are considerably more similar with explained fractions of variance of $18.0 \%$ (NCEP) and $15.4 \%$ (NorESM1-M). This pattern is dominated by a strong monopole over the central North Atlantic with a weaker monopole of the opposite sign over central Europe, and does not appear to have a clear counterpart in the hemispheric EOFs or to any established regional flow regime patterns.

To summarise the EOF analysis, the model's Arctic Oscillation is slightly too strong with an associated NAO-like pattern displaced towards the east over Europe, and it has too much variability. Furthermore, relative to COWL and the geographically correct NAO-pattern, the model produces too strong variability associated with the correctly placed PNA pattern. A sectorial EOF-analysis gives similar results for the leading EOF as the hemispheric analysis with respect to the displaced NAO-like pattern, probably because COWL is a truly hemispheric pattern.

These differences between the EOFs of NCEP and NorESM1-M can be associated with systematic errors in the storminess and the blocking occurrence over the North Atlantic Ocean and Europe mentioned in Sects. 7.1 and 7.2. The eastward displacement of parts of the NAO-pattern is, in particular, associated with the too zonal storminess pattern and 
the under-representation of blocking in the European-North Atlantic region.

Figure 15 shows the time series of the decomposition of monthly $500 \mathrm{hPa}$ geopotential height anomalies from NorESM1-M on the respective EOF1, EOF2 and EOF4 with the sign shown in Fig. 14. The data are from the three historical ensemble members and the RCP8.5 scenario for the years 2071-2100. These data include the inter-annual (and longer) trends and the systematic differences between the historical and the scenario, but not the seasonal variations. Since all the anomalies are calculated with respect to the same climatology, defined by the three historical ensemble members for 1976-2005, a given value of the component identifies an exact monthly state, irrespective of the data source. The main curves in the diagrams are the 10-yr moving averages of the components. If a coloured curve lies outside of the range of the three historical ensemble members, this may indicate that the scenario assumption (RC8.5) leads to systematic differences from internal natural variability.

For PC1, this is clearly not the case, and neither for PC3 (not shown). For PC2 and PC4, however, there are indications of systematic differences, although less clear for the latter. One possible interpretation is that in the RCP8.5 climate towards the end of the 21st century, positive phase PNA may occur less frequently or the negative phase PNA may occur more often. Furthermore, but with less confidence, positive phase NAO may occur more often or negative phase NAO less frequently. More investigations of the significance of this and on probability density functions for the different combinations of PCs are ongoing.

Finally, Fig. 15 also includes the components of anomalies associated with the historical single forcing experiments. Even though there are some signs of opposite results for the GHG and the aerosol experiments, none of these are outside the ranges of natural variability defined by the three ensemble members with all forcing components included.

\subsection{ENSO}

The "El Niño Southern Oscillation" phenomenon is a dominant mode of interannual climate variability based in the tropical Pacific which is associated with far reaching atmospheric tele-connections (Trenberth, 1997). The amplitude (Trenberth and Shea, 1987; Wang, 1995), the frequency of occurrence, and the pattern structure (An and Wang, 2000) are modulated on multi-decadal timescales. Nevertheless, it is a well recognised pattern of variability with large impacts on the weather over the western equatorial South America. It also has considerable remote impacts (Trenberth et al., 1998) showing up as a pattern in the NH extra-tropical troposphere reminiscent of the PNA internal mode of variability although the patterns of the ENSO-response and the PNA are different (Straus and Shukla, 2002). The annual global mean surface air temperature is influenced by the ENSO phase.
Bentsen et al. (2012) show that for the NINO3.4 index NorESM1-M simulates variability on shorter time-scales (2$4 \mathrm{yr}$ ) than the HadISST observations (3-7 yr, Rayner et al., 2003). It has not been investigated to what extent this is dominated by model errors or if it can be related to interdecadal modes of variability (An and Wang, 2000). However, the recent analysis by Kim and $\mathrm{Yu}$ (2012) indicates that both modes of the ENSO variability are represented in the NorESM1-M simulations, as one of the 9 out of 20 CMIP5 models.

Figure 16 shows the time series of the NINO3.4 index for HadISST data, and from NorESM1-M, the piControl, the Historic1 and the RCP8.5. It is possible to identify a more frequent occurrence of ENSO events in the piControl and Historic1 simulations compared to HadISST. A difference between the time series for RCP8.5 and either Historic1 or piControl is less evident even though both amplitudes and return periods appear slightly reduced in the scenario. To the extent that it is correct to associate warm-phase ENSO with a positive PNA pattern, this result is consistent with the EOFanalysis in Sect. 6.3.

The spectra in Fig. 16b also indicate such changes. There are two peaks in the piControl, a primary peak around $3 \mathrm{yr}$ and a secondary around 6-7 yr. Except for RCP4.5, the two peaks are less distinct in the scenarios. For RCP4.5 the two peaks appear distinct with a smaller difference between them, but both peaks occur at shorter periods than in piControl. There are also signs of less energy on periods longer than a decade for all RCPs except RCP6.0.

Further investigations with a larger number of ensemble members are required to establish the significance of these changes. The significant biases in the model simulations also reduce the confidence in the changes, even though they are internally consistent and the preliminary study by Guilyardi et al. (2012) confirms that NorESM1-M is one of the two out of 14 CMIP5 models which simulate significantly reduced ENSO variability (in that case, the NINO3 index) for the abrupt $4 \times \mathrm{CO}_{2}$ experiment, and close to significantly reduced for the gradual experiment.

\section{Summary and conclusions}

This paper presents a wide range of results of simulations with the new global climate model NorESM1-M. The companion paper by Bentsen et al. (2012) presents the basic features of the model, together with validation studies, while we have presented and discussed different aspects of the model's properties concerning the climate sensitivity and response to prescribed changes that lead to radiative forcing. We believe that the results from CMIP5 experiments with NorESM1-M, which are only discussed to some extent in this paper, are valuable contributions to the development of climate system science, as well as to the total evaluation of possible human induced climate change. The 

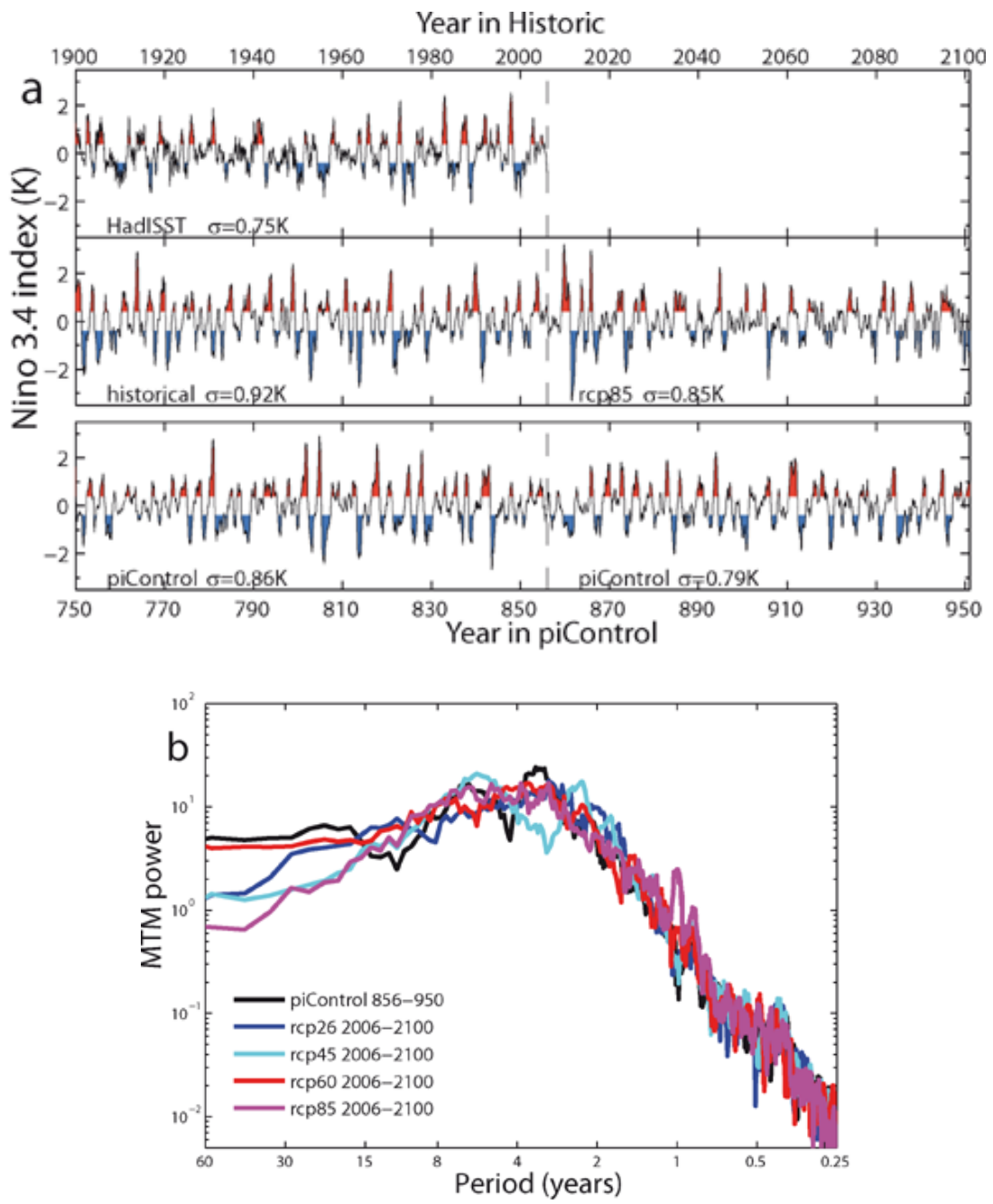

Fig. 16. Panel (a) shows time series of detrended monthly SST anomalies of the NINO3.4 region $\left(5^{\circ} \mathrm{S}-5^{\circ} \mathrm{N}, 170-120^{\circ} \mathrm{W}\right)$. The anomalies are found by subtracting the monthly means for the whole time series. Red (blue) colours indicate that anomalies are larger (smaller) than $+0.4 \mathrm{~K}(-0.4 \mathrm{~K})$, see Trenberth (1997) for recommendations. Upper time series shows Hadley Centre Sea Ice and Sea Surface Temperature data set (HadISST; Rayner et al., 2003) for years 1900-2005; middle time series consist of NorESM1-M Historic1 for years 1900-2005 continued with NorESM1-M RCP8.5 for years 2006-2100; lower time series displays NorESM1-M piControl for years 750-950. Panel (b) shows power spectra of the NINO3.4 index (the SST anomalies normalised with its standard deviation) using the multi-taper method of Ghil et al. (2002) with resolution $p=4$ and number of tapers $t=7$. Data sources are NorESM1-M piControl years 856-950 (black), and NorESM1-M RCP2.6 (blue), RCP4.5 (cyan), RCP6.0 (red), and RCP8.5 (magenta) for years 2006-2100.

data are open for anyone to download and analyse from http://cmip-pcmdi.llnl.gov/cmip5/index.html.

The clouds in the NorESM1-M tend to dampen the response to GHG forcing $\left(-0.09 \mathrm{Wm}^{-2} \mathrm{~K}^{-1}\right)$, as the longwave cloud response is considerably smaller than the negative short-wave response. The clear-sky response is negative $\left(-1.02 \mathrm{Wm}^{-2} \mathrm{~K}^{-1}\right)$, in close agreement with other models (Andrews et al., 2012). The model has a strong Atlantic meridional overturning circulation (AMOC) of $30.8 \mathrm{~Sv}$ averaged over the piControl simulation period. This contributes to an efficient transport of heat into the deep oceans and reduces the heat available for increasing the surface temperature and to melt ice and snow. Exceptions are seen adjacent to major deep water formation regions, such as in the Atlantic sector of the Arctic and in Northwest Europe, where strong convergence of warm water in the upper ocean levels may occur. The two estimates we have made of the equilibrium climate sensitivity are both slightly lower than $2.9 \mathrm{~K}$ for a long-term adjustment to an abrupt doubling of $\mathrm{CO}_{2}$. The transient climate sensitivity is estimated at slightly less than $1.4 \mathrm{~K}$ for gradual $\mathrm{CO}_{2}$-increase until doubling. We argue that the latter may be an underestimate since very slow feedback processes may occur in response to a reduction of AMOC, which will gradually decrease the efficiency of deep ocean heat uptake. Nevertheless, NorESM1-M is amongst the least sensitive global climate models (Andrews et al., 2012). 
We have also seen that the projections of global temperature increase based on RCP scenarios are substantially smaller than in most other global climate models contributing to CMIP5, although inside one standard deviation below the ensemble mean. In addition to the low climate sensitivity, NorESM1-M also includes the predominant cooling of aerosols, both the direct effect and the indirect effects of pure water clouds, although their magnitude in the present model version is quite moderate (Kirkevåg et al., 2013). The geographical distribution of the projected warming in the scenarios shows the well-known pattern of a stronger warming over the continents than the oceans, and a considerable amplification in the Arctic. The response in sea-ice is projected to be considerably larger in the Arctic than the Antarctic, and the extent in September is reduced to less than half by 2100 for three of the four RCP scenarios. For RCP8.5 this annual minimum is reduced to zero. Even though the winter maximum in March is relatively much less reduced, this will mean that the major extent of the winter Arctic sea-ice is generated during the same season.

For precipitation the largest response in the RCP scenarios towards the end of the 21 st century is simulated at low latitudes, with an increase in the tropics and a decrease in the subtropics. In the extra-tropics and the high latitudes, precipitation is projected to increase, but in the NH summer the subtropical drying is extended northwards to mid-latitudes, including southern parts of North America and Europe. Projections of gross budget numbers in the atmospheric water cycle indicate intensification of all components except the evaporation from land. This reflects that the occurrences of both dry spells and high precipitation intensities increase over land, while widespread medium precipitation intensities probably occur less frequently.

The increased precipitation and melting in the Arctic will influence the thermohaline forcing of the deep water formation and, thus, the strength of the AMOC. All the $\mathrm{RCP}$-scenarios are projected to lead to significantly reduced AMOC. In RCP8.5, AMOC is reduced by ca. one third by 2100, and in RCP4.5, which was run to 2300 with a stabilisation scenario after 2100 , the AMOC levels off at about $15-17 \%$ lower intensity. Since NorESM1-M probably overestimates the AMOC strength, there are doubts about the reliability of these results.

Extra-tropical precipitation climatology and, in particular, the occurrence of extreme precipitation and droughts, are associated with anomalies in storminess and blocking occurrence. The model is found to generally underestimate the variability in the zones of extra-tropical storminess, and a considerable part of this bias is linked to errors in the SSTsimulations. The regional patterns of storminess are also too zonal over the North Atlantic Ocean. This is consistent with the underestimated frequency of blocking over the North Atlantic Ocean and western Europe. Other recent investigations indicate that this can be related to too coarse horizontal resolution (Jung et al., 2012). Under RCP scenarios, NorESM1-
M generally projects a northward displacement of the storminess. For the most extreme scenario (RCP8.5), an increased blocking occurrence is found in the European-Atlantic sector in spring and further extended over Eurasia during summer.

The leading EOF of the $500 \mathrm{hPa}$ geopotential height during winter, representing the northern annular mode (NAM), has some pattern errors that can be associated with the systematic errors of the storminess. Furthermore, while the second EOF is dominated by a pattern reminiscent of the Pacific North American (PNA) pattern, the main influence of the North Atlantic Oscillation (NAO) turns up in the fourth EOF. From NCEP re-analysis data, the second EOF contains the main pattern of the NAO in addition to PNA. Under the RCP8.5 scenario towards 2100, there are indications that the average NAO index will increase (more positive and fewer negative events) and the average PNA index will decrease (more negative and fewer positive). The first result is consistent with the changes in storminess, while changes in blocking are insignificant in winter. The reduced PNA can be associated with the reduced amplitude of the projected NINO3.4 index, even though both the change in ENSO and the relation between ENSO and PNA are associated with low confidence.

Two of the single forcing experiments for the historical period have been addressed: the GHG only and the aerosol only. The response pattern in surface air temperature by 19762005 compared to the pre-industrial control run is similar, but with opposite sign. This is to a large extent also true for precipitation, but there are important exceptions at low latitudes. The model simulates a southward displacement of ITCZ due to aerosol forcing, and in particular during NH summer. This change may partly cancel and partly reinforce changes caused by GHG alone. Reinforcements are simulated in the northern hemispheric subtropics with reduced precipitation and increased droughts, and at the southern flank of the ITCZ in the Pacific Ocean with increased precipitation. In consequence, the double ITCZ systematic error seen in many models (also CCSM4, Gent et al., 2011) is reduced in NorESM1-M partly due to the impact of aerosols (see Bentsen et al., 2012).

Acknowledgements. This work has been supported by the Research Council of Norway through the EarthClim (207711/E10) and NOTUR/NorStore projects, the Center for Climate Dynamics at the Bjerknes Centre, and through the European Commission FP7 projects PEGASOS (FP7-ENV-2010-265148) and ACCESS (FP7-ENV-2010-265863). The development of both versions of NorESM1 has been possible because of the granted early access to the later public versions of the CCSM4 and CESM1. We are particularly grateful to P. J. Rasch, A. Gettelman, J. F. Lamarque, S. Ghan, M. Vertenstein, B. Eaton, M. Flanner, and others, for invaluable advice on numerous scientific and technical issues, and the support by the CESM programme directors during the development period, P. Gent and J. Hurrel. We are grateful for contributions during the development of NorESM1 by K. Alterskjær, A. Ekman, C. Heinze, C. Hoose, Ø. Hov, D. Nilsson, O. H. Otterå, D. Olivié, 
C. Roelandt, M. Simonsen, H. Struthers, T. Storelvmo, J. Berger, J. Su, and J. Tjiputra.

Section 7.3 in this paper is intended to be part of a Ph.D. thesis at the University of Oslo (M. Sand) in agreement with all the co-authors.

Edited by: O. Marti

\section{References}

Adler, R. F., Huffman, G. J., Chang, A., Ferraro, R., Xie, P., Janowiak, J., Rudolf, B., Schneider, U., Curtis, S., Bolvin, D., Gruber, A., Susskind, J., and Arkin, P.: The Version 2 Global Precipitation Climatology Project (GPCP) Monthly Precipitation Analysis (1979-Present), J. Hydrometeor., 4, 1147-1167, 2003.

Ammann, C. M., Meehl, G. A., Washington, W. M., and Zender, C.: A monthly and latitudinally varying volcanic forcing dataset in simulations of 20th century climate, Geophys. Res. Lett., 30, 1657, doi:10.1029/2003GL016875, 2003.

An, S.-I. and Wang, B.: Interdecadal change of the structure of the ENSO mode and its impact on the ENSO frequency, J. Clim., 13, 2044-2055, 2000.

Andrews, T., Gregory, J. M., Webb, M. J., and Taylor, K. E.: Forcing, feedbacks and climate sensitivity in CMIP5 coupled atmosphere-ocean climate models, Geophys. Res. Lett., 39, L09712, Doi:10.1029/2012g1051607, 2012.

Assmann, K. M., Bentsen, M., Segschneider, J., and Heinze, C.: An isopycnic ocean carbon cycle model, Geosci. Model Dev., 3, 143-167, doi:10.5194/gmd-3-143-2010, 2010

Barnes, E. A., Slingo, J., and Woollings, T. J.: A methodology for the comparison of blocking climatologies across indices, models and climate scenarios, Climate Dyn., 38, 2467-2481, doi:10.1007/s00382-011-1243-6, 2012.

Barnston, A. G. and Livezey, R. E.: Classification, Seasonality and Persistence of Low-Frequency Atmospheric Circulation Patterns, Mon. Weather Rev., 115, 1083-1126, doi:10.1175/15200493(1987)115;1083:CSAPOL $; 2.0 . C O ; 2,1987$.

Bentsen, M., Bethke, I., Debernard, J. B., Iversen, T., Kirkevåg, A., Seland, Ø., Drange, H., Roelandt, C., Seierstad, I. A., Hoose, C., and Kristjánsson, J. E.: The Norwegian Earth System Model, NorESM1-M - Part 1: Description and basic evaluation, Geosci. Model Dev. Discuss., 5, 2843-2931, doi:10.5194/gmdd-5-28432012, 2012.

Bethke, I., Furevik, T., and Drange, H.: Towards a more saline North Atlantic and a fresher Arctic under global warming, Geophys. Res. Lett., 33, L21712, doi:10.1029/2006GL027264, 2006.

Bitz, C. M., Shell, K. M., Gent, P. R., Bailey, D. A., Danabasoglu, G., Armour, K. C., Holland, M. M., and Kiehl, J. T.: Climate Sensitivity of the Community Climate System Model, Version 4, J. Climate, 25, 3053-3070, doi:10.1175/JCLI-D-11-00290.1, 2012.

Bjørnsson, H. and Venegas, S. A.: A manual for EOF and SVD analyses of climate data, McGill University, CCGCR Report No. $97-$ 1, Montréal, Québec, 52 pp., 1997.

Blackmon, M. L.: A climatological spectral study of the $500 \mathrm{mb}$ geopotential height of the Northern Hemisphere, J. Atmos. Sci., 33, 1607-1623, 1976.
Boer, G. J. and Yu, B.: Climate sensitivity and response, Clim. Dynam., 20, 415-429, doi:10.1007/s00382-002-0283-3, 2003.

Branstator, G. and Selten, F.: "Modes of Variability" and Climate Change, J. Climate, 22, 2639-2658, doi:10.1175/2008JCLI2517.1, 2009.

Bratseth, A. M.: Eddy Acceleration of the Mean Flow in the Atmosphere, J. Atmos. Sci., 58, 3328-3339, 2001.

Bratseth, A. M.: Zonal-mean transport characteristics of ECMWF re-analysis data, Q. J. R. Meteorol. Soc., 129, 2331-2346, doi:10.1256/qj.02.90, 2003.

Chang, E. K. M., Lee, S., and Swanson, K. L.: Storm Track Dynamics, J. Climate, 15, 2163-2183, 2002.

Corti, S., Molteni, F., and Palmer, T. N.: Signature of recent climate change in frequencies of natural atmospheric circulation regimes, Nature, 398, 799-802, 1999.

Corti, S., Gualdi, S., and Navarra, A.: Analysis of the mid-latitude weather regimes in the 200-year control integration of the SINTEX model, Annals Geophys., 46, 27-37, 2003.

Curry, R. and Mauritzen, C.: Dilution of the Northern North Atlantic Ocean in Recent Decades, Science, 308, 1772-1774, doi:10.1126/science.1109477, 2005.

D’Andrea, F., Tibaldi, S., Blackburn, M., Boer, G., Déqué, M., Dix, M. R., Dugas, B., Ferranti, L., Iwasaki, T., Kitoh, A., Pope V., Randall, D., Roeckner, E., Strauss, D., Stern, W., Van den Dool, H., and Williamson, D.: Northern Hemisphere atmospheric blocking as simulated by 15 atmospheric general circulation models in the period 1979-1988, Climate Dynam., 14, 385-407, 1998

Fetterer, F., Knowles, K., Meier, W., and Savoie, M.: Sea Ice Index Boulder, CO: National Snow and Ice Data Center, Digital media, 2009.

Flanner, M. G. and Zender, C. S.: Linking snowpack microphysics and albedo evolution, J. Geophys. Res., 111, D12208, doi:10.1029/2005JD006834, 2006.

Furevik, T., Bentsen, M., Drange, H., Kindem, I. K. T., Kvamstø, N. G., and Sorteberg, A.: Description and evaluation of the bergen climate model: ARPEGE coupled with MICOM, Clim. Dynam., 21, 27-51, doi10.1007/s00382-003-0317-5, 2003.

Gent, P. R., Danabasoglu, G., Donner, L. J., Holland, M. M., Hunke, E. C., Jayne, S. R., Lawrence, D. M., Neale, R. B., Rasch, P. J., Vertenstein, M., Worley, P. H., Yang, Z.-L., and Zhang, M.: The Community Climate System Model Version 4. J. Climate, 24, 4973-4991, doi:10.1175/2011JCLI4083.1, 2011.

Gettelman, A., Kay, J. E., and Shell, K. M.: The Evolution of Climate Sensitivity and Climate Feedbacks in the Community Atmosphere Model, J. Climate, 25, 1453-1469, doi:10.1175/JCLID-11-00197.1, 2012.

Ghil M., Allen, R. M., Dettinger, M. D., Ide, K., Kondrashov, D., Mann, M. E., Robertson, A., Saunders, A., Tian, Y., Varadi, F., and Yiou, P.: Advanced spectral methods for climatic time series, Rev. Geophys., 40, 3.1-3.41, doi:10.1029/2000RG000092, 2002.

Gimeno, L., Nieto, R., Drumond, A., Durán-Quesada, A. M., Stohl, A., Sodemann, H., and Trigo, R. M.: A Close Look at Oceanic Sources of Continental Precipitation, Eos Transactions AGU, 92, 193-195, 2011.

Giorgi, F., Im, E.-S., Coppola, E., Diffenbaugh, N. S., Gao, X . J., Mariotti, L., and Shi, Y.: Higher Hydroclimatic Intensity with Global Warming, J. Climate, 24, 5309-5324, doi:10.1175/2011JCLI3979.1, 2011. 
Gregory, J. M., Ingram, W. J., Palmer, M. A., Jones, G. S., Stott, P. A., Thorpe, R. B., Lowe, J. A., Johns, T. C., and Williams, K. D.: A new method for diagnosing radiative forcing and climate sensitivity, Geophys. Res. Lett., 31, L03205, doi:10.1029/2003GL018747, 2004.

Guilyardi, E., Bellenger, H., Collins, M., Ferrett, S., Cai, W., and Wittenberg, A.: A first look at ENSO in CMIP5, CLIVAR Exchanges No. 58, 17, 29-32, available at: http://www.gfdl. noaa.gov/ atw/yr/2012/guilyardi_etal_2012_clivex.pdf last access: February 2012, 2012.

Hannachi, A., Jolliffe, I. T., and Stephenson, D. B.: Empirical orthogonal functions and related techniques in atmospheric science: A review, Internat. J. Clim., 27, 1119-1152, 2007.

Hofmann, M. and Rahmstorf, S.: On the stability of the Atlantic meridional overturning circulation, P. Natl. Acad. Sci. USA, 106, 20584-20589, 2009.

Hoose, C., Kristjánsson, J. E., Iversen, T., Kirkevåg, A., Seland, Ø., and Gettelman, A.: Constraining cloud droplet number concentration in GCMs suppresses the aerosol indirect effect, Geophys. Res. Lett., 36, L12807, doi:10.1029/2009GL038568, 2009.

Houghton, J. T., Ding, Y., Griggs, D. J., Noguer, M., van der Linden, P. J., Dai, X., Maskell, K., and Johnson, C. A.: Climate Change 2001: The Scientific Basis. Contribution of Working Group I to the Third Assessment Report of the Intergovernmental Panel on Climate Change. Cambridge University Press. 881 pp. 2001.

Hurrell, J. W., Hack, J. J., Phillips, A. S., Caron, J., and Yin, J.: The Dynamical Simulation of the Community Atmosphere Model Version 3 (CAM3), J. Climate, 19, 2162-2183, 2006.

Iversen, T. and Seland, Ø.: A scheme for process-tagged $\mathrm{SO}_{4}$ and BC aerosols in NCAR-CCM3: Validation and sensitivity to cloud processes, J. Geophys. Res., 107, 4751, doi:10.1029/2001JD000885, 2002.

Iversen, T. and Seland, Ø.: Correction to "A scheme for processtagged SO4 and BC aerosols in NCAR-CCM3. Validation and sensitivity to cloud processes", J. Geophys. Res., 108, 4502, doi:10.1029/2003JD003840, 2003.

Iversen, T., Kristiansen, J., Jung, T., and Barkmeijer, J.: Optimal atmospheric forcing perturbations for the cold-ocean warm-land pattern, Tellus A, 60, 528-546, doi:10.1111/j.16000870.2008.00310.x, 2008.

Jiang, J. H., Su, H., Zhai, C., Perun, V., Del Genio, A. D., Nazarenko, L. S., Donner, L. J., Horowitz, L. W., Seman, C. J., Cole, J., Gettelman, A., Ringer, M. A., Rotstayn, L. D., Jeffrey, S. J., Wu, T., Brient, F., Dufresne, J.-L., Kawai, H., Koshiro, T., Masahiro, W., L'Écuyer, T. S., Volodin, E. M., Iversen, T., Drange, H., dos Santos Mesquita, M., Read, W. G., Waters, J. W., Tian, B., Teixeira, J., and Stephens, G. L.: Evaluation of cloud and water vapor simulations in CMIP5 climate models using NASA "A-Train" satellite observations, J. Geophys. Res., 117, D14105, doi:10.1029/2011JD017237, 2012.

Jung, T., Miller, M. J., Palmer, T. N., Towers, P., Wedi, N., Achuthavarier, D., Adams, J. M., Altshuler, E. L., Cash, B. A., Kinter III, J. L., Marx, L., Stan, C., and Hodges, K. I.: High-Resolution Global Climate Simulations with the ECMWF Model in Project Athena: Experimental Design, Model Climate, and Seasonal Forecast Skill, J. Climate, 25, 3155-3172, doi:10.1175/JCLI-D-11-00265.1, 2012.

Kalnay, E., Kanamitsu, M., Kistler, R., Collins, W., Deaven, D., Gandin, L., Iredell, M., Saha, S., White, G., Woollen, J., Zhu, Y.,
Leetmaa, A., Reynolds, R., Chelliah, M., Ebisuzaki, W., Higgins, W., Janowiak, J., Mo, K. C., Ropelewski, C., Wang, J., Jenne, R., and Joseph, D.: The NCEP/NCAR 40-Year Reanalysis Project, B. Am. Meteorol. Soc., 77 437-471, 1996.

Kay, J. E., Holland, M. M., Bitz, C. M., Blanchard-Wrigglesworth, E., Gettelman, A., Conley, A., and Bailey, D.: The influence of local feedbacks and northward heat transport on the equilibrium Arctic climate response to increased greenhouse gas forcing, $\mathrm{J}$ Climate, 25, 5433-5450, doi:10.1175/JCLI-D-11-00622.1, 2012.

Kim, S. T. and Yu, J.-Y.: The Two Types of ENSO in CMIP5 Models, Geophys. Res. Lett., 39, L11704, doi:10.1029/2012GL052006, 2012.

Kirkevåg, A. and Iversen, T.: Global direct radiative forcing by process-parameterized aerosol optical properties, J. Geophys. Res., 107, 4433, doi:10.1029/2001JD000886, 2002.

Kirkevåg, A., Iversen, T., Seland, Ø., Debernard, J. B., Storelvmo, T., and Kristjánsson, J. E.: Aerosol-cloud-climate interactions in the climate model CAM-Oslo, Tellus A, 60, 492-512, doi:10.1111/j.1600-0870.2008.00313.x, 2008a.

Kirkevåg, A., Iversen, T., Kristjànsson, J. E., Seland, Ø., and Debernard, J. B.: On the additivity of climate response to anthropogenic aerosols and $\mathrm{CO} 2$, and the enhancement of future global warming by carbonaceous aerosols, Tellus A, 60, 513 527, doi:10.1111/j.1600-0870.2008.00308.x, 2008b.

Kirkevåg, A., Iversen, T., Seland, Ø., Hoose, C., Kristjánsson, J. E., Struthers, H., Ekman, A. M. L., Ghan, S., Griesfeller, J., Nilsson, E. D., and Schulz, M.: Aerosol-climate interactions in the Norwegian Earth System Model - NorESM1-M, Geosci. Model Dev., 6, 207-244, doi:10.5194/gmd-6-207-2013, 2013.

Kristjánsson, J. E.: Studies of the aerosol indirect effect from sulphate and black carbon aerosols, J. Geophys. Res., 107, 4246, doi:10.1029/2001JD000887, 2002.

Kristjánsson, J. E., Iversen, T., Kirkevåg, A., Seland, Ø., and Debernard, J.: Response of the climate system to aerosol direct and indirect forcing: Role of cloud feedbacks, J. Geophys. Res., 110, D24206, doi:10.1029/2005JD006299, 2005.

Lamarque, J.-F., Bond, T. C., Eyring, V., Granier, C., Heil, A., Klimont, Z., Lee, D., Liousse, C., Mieville, A., Owen, B., Schultz, M. G., Shindell, D., Smith, S. J., Stehfest, E., Van Aardenne, J., Cooper, O. R., Kainuma, M., Mahowald, N., McConnell, J. R., Naik, V., Riahi, K., and van Vuuren, D. P.: Historical (1850-2000) gridded anthropogenic and biomass burning emissions of reactive gases and aerosols: methodology and application, Atmos. Chem. Phys., 10, 7017-7039, doi:10.5194/acp10-7017-2010, 2010.

Lean, J., Rottman, G., Harder, J., and Kopp, G.: SORCE contributions to new understanding of global change and solar variability, Sol. Phys., 230, 27-53, 2005.

Lejanäs, H. and Økland, H.: Characteristics of Northern Hemisphere blocking as determined from a long series of observational data, Tellus A, 35, 350-362, 1983.

Matsueda, M., Mizuta, R., and Kusunoki, S.: Future change in wintertime atmospheric blocking simulated using a 20-km-mesh atmospheric global circulation model, J. Geophys. Res., 114, D12114, doi:10.1029/2009JD011919, 2009.

Medhaug, I. and Furevik, T.: North Atlantic 20th century multidecadal variability in coupled climate models: sea surface temperature and ocean overturning circulation, Ocean Sci., 7, 389404, doi:10.5194/os-7-389-2011, 2011. 
Meehl, G. A., Covey, C., McAvaney, B., Latif, M., and Stouffer, R. J.: Overview of the coupled model intercomparison project, B. Am. Meteorol. Soc., 86, 89-93, doi:10.1175/BAMS-86-1-89, 2005.

Meehl, G. A., Washington, W. M., Arblaster, J. M., Hu, A., Teng, H., Tebaldi, C., Sanderson, B., Lamarque, J.-F., Conley, A., Strand, W. G., and White III, J. B.: Climate System Response to External Forcings and Climate Change Projections in CCSM4, J. Climate, 25, 3661-3683, doi:10.1175/JCLI-D-11-00240.1, 2012.

Molteni, F., Kucharski, F., and Corti, S.: On the predictability of flow-regime properties on interannual to interdecadal timescales, in: Predictability of Weather and Climate, edited by: Palmer, T. and Hagedorn, R., Cambridge University Press, 365-389, 2006.

Monahan, A. H., Fyfe, J. C., Ambaum, M. H. P., Stephenson, D. B., and North, G. R.: Empirical orthogonal functions: the medium is the message, J. Climate, 22, 6501-6514, 2009.

Munk, W. and Wunsch, C.: Abyssal recipes II: energetics of tidal and wind mixing, Deep-Sea Res. I, 45, 1977-2010, 1998.

Murphy, D. M.: Transient response of the Hadley Centre coupled ocean-atmosphere model to increasing carbon dioxide: Part III. Analysis of global-mean response using simple models, J. Climate, 8, 495-514, doi:10.1175/15200442(1995)008;0496:TROTHC i2.0.CO;2, 1995.

Myhre, G., Samset, B. H., Schulz, M., Balkanski, Y., Bauer, S., Berntsen, T. K., Bian, H., Bellouin, N., Chin, M., Diehl, T., Easter, R. C., Feichter, J., Ghan, S. J., Hauglustaine, D., Iversen, T., Kinne, S., Kirkevåg, A., Lamarque, J.-F., Lin, G., Liu, X., Lund, M. T., Luo, G., Ma, X., van Noije, T., Penner, J. E., Rasch, P. J., Ruiz, A., Seland, Ø., Skeie, R. B., Stier, P., Takemura, T., Tsigaridis, K., Wang, P., Wang, Z., Xu, L., Yu, H., Yu, F., Yoon, J.-H., Zhang, K., Zhang, H., and Zhou, C.: Radiative forcing of the direct aerosol effect from AeroCom Phase II simulations, Atmos. Chem. Phys., 13, 1853-1877, doi:10.5194/acp-13-18532013, 2013. .

Neale, R. B., Richter, J. H., and Jochum, M.: The impact of convection on ENSO: From a delayed oscillator to a series of events, J. Climate, 21, 5904-5924, 2008

Neale, R. B, Richter, J. H., Conley, A. J., Park, S., Lauritzen, P. H., Gettelman, A., Williamson, D. L., Rasch, P. J., Vavrus, S. J., Taylor, M. A., Collins, W. D., Zhang, M., and Lin, S.-J.: Description of the NCAR Community Atmosphere Model (CAM 4.0), NCAR Technical Note, NCAR/TN-485+STR, April 2010.

Neale, R. B., Richter, J. H., Park, S., Lauritzen, P. H., Vavrus, S. J., Rasch, P. J., and Zhang, M.: The mean climate of the Community Atmosphere Model (CAM4) in forced SST and fully coupled experiments, J. Climate, submitted, 2012.

Otterå, O. H., Bentsen, M., Bethke, I., and Kvamst $\varnothing$, N. G.: Simulated pre-industrial climate in Bergen Climate Model (version 2): model description and large-scale circulation features, Geosci. Model Dev. Discuss., 2, 507-549, doi:10.5194/gmdd-2507-2009, 2009.

Otterå, O. H., Bentsen, M., Drange, H., and Suo, L.: External focing as a metronome for Atlantic multidecadal variability, Nat. Geosci., 3, 688-694, doi:10.1038/NGEO955, 2010.

Palmer, T. N.: A nonlinear dynamical perspective on climate prediction, J. Climate, 12, 575-591, doi:10.1175/15200442(1999)012;0575:ANDPOC $\dot{2} 2.0 . C O ; 2,1999$.

Pelly, J. L. and Hoskins, B. J.: A new perspective on blocking, J. Atmos. Sci., 60, 743-755, 2003.
Rasch, P. J. and Kristjánsson, J. E.: A comparison of the CCM3 model climate using diagnosed and predicted condensate parameterisations, J. Climate, 11, 1587-1614, 1998.

Rasch, P. J., Coleman, D. B., Mahowald, N., Williamson, D. L., Lin, S.-J., Boville, B. A., and Hess, P.: Characteristics of atmospheric transport using three numerical formulations for atmospheric dynamics in a single GCM framework, J. Climate, 19, 2243-2266, 2006.

Rayner, N. A., Parker, D. E., Horton, E. B., Folland, C. K., Alexander, L. V., Rowell, D. P., Kent, E. C., and Kaplan, A.: Global analyses of sea surface temperature, sea ice, and night marine air temperature since the late nineteenth century, J. Geophys. Res., 108, 4407, doi:10.1029/2002JD002670, 2003.

Richter, J. H. and Rasch, P. J.: Effects of convective momentum transport on the atmospheric circulation in the Community Atmosphere Model, version 3, J. Climate, 21, 1487-1499, 2008.

Rotstayn, L. D. and Lohmann, U.: Tropical rainfall trends and the indirect aerosol effect, J. Climate, 15, 2103-2116, 2002.

Samset, B. H., Myhre, G., Schulz, M., Balkanski, Y., Bauer, S., Berntsen, T. K., Bian, H., Bellouin, N., Diehl, T., Easter, R. C., Ghan, S. J., Iversen, T., Kinne, S., Kirkevåg, A., Lamarque, J.F., Lin, G., Liu, X., Penner, J. E., Seland, Ø., Skeie, R. B., Stier, P., Takemura, T., Tsigaridis, K., and Zhang, K.: Black carbon vertical profiles strongly affect its radiative forcing uncertainty, Atmos. Chem. Phys., 13, 2423-2434, doi:10.5194/acp-13-24232013, 2013.

Scaife, A. A., Copsey, D., Gordon, C., Harris, C., Hinton, T., Keeley, S., O’Neill, A., Roberts, M., and Williams, K.: Improved Atlantic winter blocking in a climate model, Geophys. Res. Lett., 38, L23703, doi:10.1029/2011GL049573, 2011.

Schneider, B., Latif, M., and Schmittner, A.: Evaluation of Different Methods to Assess Model Projections of the Future Evolution of the Atlantic Meridional Overturning Circulation, J. Climate, 20, 2121-2132, 2007.

Seland, Ø., Iversen, T., Kirkevåg, A., and Storelvmo, T.: Aerosolclimate interactions in the CAM-Oslo atmospheric GCM and investigations of associated shortcomings, Tellus A, 60, 459-491, 2008.

Senior, C. A. and Mitchell, J. F. B.: The time-dependence of climate sensitivity, Geophys. Res. Lett., 27, 2685-2688, doi:10.1029/2000GL011373, 2000.

Stephenson, D. B., Hannachi, A., and O'Neill, A.: On the existence of multiple climate regimes, Q. J. Roy. Meteor. Soc., 130, $583-$ 605, 2004.

Stohl, A., Forster, C., and Sodemann, H.: Remote sources of water vapor forming precipitation on the Norwegian west coast at $60^{\circ} \mathrm{N}$ : A tale of hurricanes and an atmospheric river, J. Geophys. Res., 113, D05102, doi:10.1029/2007JD009006, 2008.

Storelvmo, T., Kristjánsson, J. E., Ghan, S., Kirkevåg, A., Seland, Ø., and Iversen, T.: Predicting cloud droplet number in CAM-Oslo, J. Geophys. Res., 111, D24208, doi:10.1029/2005JD006300, 2006.

Straus, D. M. and Shukla, J.: Does ENSO force the PNA?, J. Climate, 15, 2340-2358, 2002.

Struthers, H., Ekman, A. M. L., Glantz, P., Iversen, T., Kirkevåg, A., Mårtensson, E. M., Seland, Ø., and Nilsson, E. D.: The effect of sea ice loss on sea salt aerosol concentrations and the radiative balance in the Arctic, Atmos. Chem. Phys., 11, 3459-3477, doi:10.5194/acp-11-3459-2011, 2011. 
Struthers, H., Ekman, A. M. L., Glantz, P., Iversen, T., Kirkevåg, A., Seland, Ø., Mårtensson, E. M., Noone, K., and Nilsson, E. D.: Climate-induced changes in sea salt aerosol number emissions: 1870 to 2100, J. Geophys. Res., 118, 670-682, doi:10.1002/jgrd.50129, 2013.

Subramanian, A. C., Jochum, M., Miller, A. J., Murtugudde, R., Neale, R. B., and Waliser, D. E.: The Madden Julian Oscillation in CCSM4, J. Climate, 24, 6261-6282, doi:10.1175/JCLI-D-1100031.1, 2011.

Taylor, K. E., Stouffer, R. J., and Meehl, G. A.: An overview of CMIP5 and the experiment design, B. Am. Meteorol. Soc., 90, 485-498, doi:10.1175/BAMS-D-11-00094.1, 2012.

Thompson, D. W. J. and Wallace, J. M.: Annular modes in the extratropical circulation, Part I: month-to-month variability, J. Climate, 13, 1000-1016, 2000.

Tibaldi, S. and Molteni, F.: On the operational predictability of blocking, Tellus A, 42, 343-365, 1990.

Tjiputra, J. F., Roelandt, C., Bentsen, M., Lawrence, D. M., Lorentzen, T., Schwinger, J., Seland, Ø., and Heinze, C.: Evaluation of the carbon cycle components in the Norwegian Earth System Model (NorESM), Geosci. Model Dev., in press, 2013.

Trenberth, K. E.: The definition of El Niño, B. Am. Meteorol. Soc., 78, 2771-2777, 1997.

Trenberth, K. E.: Changes in precipitation with climate change, Climate Res., 47, 123-138, doi:10.3354/cr00953, 2011.

Trenberth, K. E. and Shea, D. J.: On the evolution of the Southern Oscillation, Mon. Weather Rev., 115, 3078-3096, 1987.

Trenberth, K. E., Branstator, G. W., Karoly, D., Kumar, A., Lau, N.C., and Ropelewski, C.: Progress during TOGA in understanding and modeling global teleconnections associated with tropical sea surface temperatures, J. Geophys. Res., 103, 14291-14324, doi:10.1029/97JC01444, 1998.

Trenberth, K. E., Dai, A., Rasmussen, R. M., and Parsons, D. B.: The changing character of precipitation, B. Am. Meteorol. Soc., 84, 1205-1217, 2003.

Trenberth, K. E., Jones, P. D., Ambenje, P., Bojariu, R., Easterling, D., Klein Tank, A., Parker, D., Rahimzadeh, F., Renwick, J. A., Rusticucci, M., Soden, B., and Zhai, P.: Observations: surface and atmospheric climate change, in: Climate Change 2007: The Physical Science Basis, Intergovernmental Panel on Climate Change 4th Assessment Report, edited by: Solomon, S., Qin, D., Manning, M., Chen, Z., Marquis, M., Averyt, K. B., Tignor, M., and Miller, H. L., Cambridge University Press, Cambridge, 235336, 2007.
Trenberth, K. E., Fasullo, J. T., and Mackaro, J.: Atmospheric Moisture Transports from Ocean to Land and Global Energy Flows in Reanalyses, J. Climate, 24, 4907-4924, doi:10.1175/2011JCLI4171.1, 2011.

Uppala, S. M., Kallberg, P. W., Simmons, A. J., Andrae, U., Bechtold, V. D., Fiorino, M., Gibson, J. K., Haseler, J., Hernandez, A., Kelly, G. A., Li, X., Onogi, K., Saarinen, S., Sokka, N., Allan, R. P., Andersson, E., Arpe, K., Balmaseda, M. A., Beljaars, A. C. M., Van De Berg, L., Bidlot, J., Bormann, N., Caires, S., Chevallier, F., Dethof, A., Dragosavac, M., Fisher, M., Fuentes, M., Hagemann, S., Holm, E., Hoskins, B. J., Isaksen, L., Janssen, P. A. E. M., Jenne, R., McNally, A. P., Mahfouf, J. F., Morcrette, J. J., Rayner, N. A., Saunders, R. W., Simon, P., Sterl, A., Trenberth, K. E., Untch, A., Vasiljevic, D., Viterbo, P., and Woollen, J. T.: The ERA-40 re-analysis, Q. J. Roy. Meteorol. Soc., 131, 2961-3012, 2005.

Yin, J. H.: A consistent poleward shift of the storm tracks in simulations of 21 st century climate, Geophys. Res. Lett., 32, L18701, doi:10.1029/2005GL023684, 2005.

van Vuuren, D. P., Edmonds, J., Kainuma, M., Riahi, K., Thomson, A., Hibbard, K., Hurtt, G. C., Kram, T., Krey, V., Lamarque, J.F., Masui, T., Meinshausen, M., Nakicenovic, N., Smith, S. J., and Rose, S. K.: The representative concentration pathways: an overview, Climatic Change, 109, 5-31, doi:10.1007/s10584-0110148-z, 2011.

Wallace, J. M. and Gutzler, D. S.: Teleconnections in the geopotential height field during the Northern Hemisphere winter, Mon Weather Rev., 109, 784-812, 1981.

Wallace, J. M., Zhang, Y., and Bajuk, L.: Interpretation of interdecadal trends in Northern Hemispheric surface air temperature, J. Climate, 9, 249-259, 1996.

Wang, B.: Interdecadal changes in El Nino onset in the last four decades, J. Climate, 8, 267-285. 1995.

Wang, Y.-M., Lean, J. L., and Sheeley Jr., N. R.: Modeling the Sun's magnetic field and irradiance since 1713, Astrophys. J., 625, 522-538. 2005.

Zhang, G. J. and McFarlane, N. A.: Sensitivity of climate simulations to the parameterisation of cumulus convection in the Canadian Climate Centre general circulation model, Atmos. Ocean., 33, 407-446, 1995. 